\title{
Activating Transcription Factor 4 (ATF4) Regulates Neuronal Activity by Controlling $\mathrm{GABA}_{\mathrm{B}} \mathrm{R}$ Trafficking
}

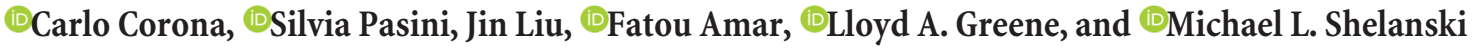 \\ Department of Pathology \& Cell Biology and the Taub Institute for Research on Alzheimer's Disease and the Aging Brain, Columbia University Medical \\ Center, New York, New York 10033
}

Activating Transcription Factor 4 (ATF4) has been postulated as a key regulator of learning and memory. We previously reported that specific hippocampal ATF4 downregulation causes deficits in synaptic plasticity and memory and reduction of glutamatergic functionality. Here we extend our studies to address ATF4's role in neuronal excitability. We find that long-term ATF4 knockdown in cultured rat hippocampal neurons significantly increases the frequency of spontaneous action potentials. This effect is associated with decreased functionality of metabotropic $G_{A B A}$ receptors $\left(G_{A B A} R s\right)$. Knocking down ATF4 results in significant reduction of $G A B A_{B} R$-induced GIRK currents and increased mIPSC frequency. Furthermore, reducing ATF4 significantly decreases expression of membrane-exposed, but not total, $\mathrm{GABA}_{\mathrm{B}} \mathrm{R}$ la and $\mathrm{lb}$ subunits, indicating that ATF4 regulates $\mathrm{GABA}_{\mathrm{B}} \mathrm{R}$ trafficking. In contrast, ATF4 knockdown has no effect on surface expression of $\mathrm{GABA}_{B} \mathrm{R} 2 \mathrm{~s}$, several $\mathrm{GABA}_{\mathrm{B}} \mathrm{R}$-coupled ion channels or $\beta 2$ and $\gamma 2 \mathrm{GABA}_{\mathrm{A}} \mathrm{Rs}$. Pharmacologic manipulations confirmed the relationship between $\mathrm{GABA}_{\mathrm{B}} \mathrm{R}$ functionality and action potential frequency in our cultures. Specifically, the effects of ATF4 downregulation cited above are fully rescued by transcriptionally active, but not by transcriptionally inactive, shRNA-resistant, ATF4. We previously reported that ATF 4 promotes stabilization of the actin-regulatory protein Cdc 42 by a transcription-dependent mechanism. To test the hypothesis that this action underlies the mechanism by which ATF4 loss affects neuronal firing rates and $\mathrm{GABA}_{\mathrm{B}} \mathrm{R}$ trafficking, we downregulated Cdc42 and found that this phenocopies the effects of ATF4 knockdown on these properties. In conclusion, our data favor a model in which ATF4, by regulating Cdc42 expression, affects trafficking of $\mathrm{GABA}_{\mathrm{B}} \mathrm{Rs}$, which in turn modulates the excitability properties of neurons.

Key words: ATF4; Cdc42; $\mathrm{GABA}_{\mathrm{B}}$ receptors; GIRK channels; neuronal excitability

Significance Statement

$\mathrm{GABA}_{B}$ receptors $\left(\mathrm{GABA}_{\mathrm{B}} \mathrm{Rs}\right)$, the metabotropic receptors for the inhibitory neurotransmitter GABA, have crucial roles in controlling the firing rate of neurons. Deficits in trafficking/functionality of $G A B A_{B} R s$ have been linked to a variety of neurological and psychiatric conditions, including epilepsy, anxiety, depression, schizophrenia, addiction, and pain. Here we show that $\mathrm{GABA}_{\mathrm{B}} \mathrm{Rs}$ trafficking is influenced by Activating Transcription Factor 4 (ATF4), a protein that has a pivotal role in hippocampal memory processes. We found that ATF4 downregulation in hippocampal neurons reduces membrane-bound $\mathrm{GABA}_{\mathrm{B}} \mathrm{R}$ levels and thereby increases intrinsic excitability. These effects are mediated by loss of the small GTPase Cdc42 following ATF4 downregulation. These findings reveal a critical role for ATF4 in regulating the modulation of neuronal excitability by $\mathrm{GABA}_{\mathrm{B}} \mathrm{Rs}$.

\section{Introduction}

Normal cognitive functions rely on the balance of neuronal excitability properties throughout the brain as well as on synaptic plasticity (Beck and Yaari, 2008). Among the many proteins re-

\footnotetext{
Received Nov. 27, 2017; revised May 29, 2018; accepted May 31, 2018.

Author contributions: M.L.S. and L.A.G. designed research; C.C., S.P., J.L., and F.A. performed research; C.C., S.P., J.L., and F.A. analyzed data; M.L.S. and L.A.G. wrote the paper.

This work was supported in party by National Institutes of Health National Institute of Neurological Disorders and Stroke Grants R01NS033689 and R01NS072050, Taub Institute for Research in Alzheimer's Disease, and Marilyn and Henry Taub Foundation. We thank Drs. Ottavio Arancio and Asa Abeliovich for providing equipment for electrophysiological experiments.

The authors declare no competing financial interests.
}

ported to influence cognition, mounting evidence suggests a pivotal role for Activating Transcription Factor 4 (ATF4), a ubiquitously expressed member of the ATF/CREB transcription factor family of basic leucine zipper proteins. In addition to its well-known functions as a stress-induced protein (Ameri and

Correspondence should be addressed to Dr. Michael L. Shelanski, Department of Pathology \& Cell Biology and the Taub Institute for Research on Alzheimer's Disease and the Aging Brain, Columbia University Medical Center, New York, NY10033. E-mail: mls7@columbia.edu.

Silvia Pasini's present address: Department of Ophthalmology and Visual Science, Vanderbilt University Medical Center, Nashville, TN 37232

DOI:10.1523/JNEUROSCI.3350-17.2018

Copyright $\odot 2018$ the authors $\quad 0270-6474 / 18 / 386102-12 \$ 15.00 / 0$ 
Harris, 2008), a number of studies have implicated ATF4 in synaptic plasticity and in learning and memory. Depending on cellular context, ATF4 has been characterized as either an inhibitor or promoter of synaptic plasticity (Pasini et al., 2015). Similarly divergent suggestions about ATF4's functions in learning and memory have been advanced, but these are largely based on indirect and nonselective manipulation of ATF4 activity or expression (Chen et al., 2003; Costa-Mattioli et al., 2007). To probe directly ATF4's role in normal brain function, we have monitored the consequences of its knockdown or knock-out in neuronal culture and in animals. This has led to observations that ATF4 plays a role in regulation of mushroom dendritic spine density as well as in synaptic glutamatergic function (Liu et al., 2014). These effects appeared to be due to ATF4's direct transcriptional regulation of RhoGDI $\alpha$ (product of the Arhgdia gene), which in turn affects stability of the Rho family member Cdc42 that is involved in regulation of the actin cytoskeleton (Pasini et al., 2016). At the physiological level, loss of ATF4 manifested in reduced frequency and amplitude of mEPSCs, followed by defective LTP and LTD as well as in memory deficits (Pasini et al., 2015). Of relevance, similar deficiencies in plasticity and memory have been observed after conditional Cdc42 knock-out in brain (Kim et al., 2014). In the context of ATF4's role in neuronal functionality, one area of interest is in its relation to $\mathrm{GABA}_{\mathrm{B}}$ receptors $\left(\mathrm{GABA}_{\mathrm{B}} \mathrm{Rs}\right)$, the G-protein-linked metabotropic receptors for the inhibitory neurotransmitter GABA. Several studies have shown direct association of $\mathrm{GABA}_{\mathrm{B}}$ Rs with ATF4 (Nehring et al., 2000; White et al., 2000; Vernon et al., 2001; Ritter et al., 2004), whereas another study reported that ATF4 differentially regulates activity of promoters for the $\mathrm{GABA}_{\mathrm{B}}$ Rs subunits $1 \mathrm{a}$ and $1 \mathrm{~b}$ (Steiger et al., 2004). $\mathrm{GABA}_{\mathrm{B}} \mathrm{Rs}$ are widely expressed in brain and regulate neuronal excitability by modulating activity of G-protein-gated inwardly rectifying $\mathrm{K}^{+}$channels (GIRKs), voltage-gated $\mathrm{Ca}^{2+}$ channels, and adenylyl cyclase (Gassmann and Bettler, 2012). Activation of $\mathrm{GABA}_{\mathrm{B}} \mathrm{Rs}$ has been reported to hyperpolarize and decrease the threshold, whereas deactivation of the receptors increases the threshold required to generate an action potential (Ladera et al., 2008). Thus, alterations of $\mathrm{GABA}_{\mathrm{B}} \mathrm{R}$ trafficking/functionality have the potential to significantly alter intrinsic neuronal excitability and brain function. In this work, we have investigated the role of ATF4 in neuronal excitability. We find that ATF4 knockdown in cultured hippocampal neurons significantly increases their firing rate and that this appears to be due to reduced trafficking of $\mathrm{GABA}_{\mathrm{B}} \mathrm{R}$ to the cell surface. These effects in turn appear to be a consequence of ATF4's regulation of Cdc42 stability.

\section{Materials and Methods}

Cell cultures. Primary hippocampal cultures were prepared as previously described (Liu et al., 2014). Briefly, hippocampi were dissected from E18 rat embryos of either sex; after dissociation, neurons were plated on poly-D-lysine-coated 12 -well plates at the density of $3 \times 10^{5}$ cells/well. Neurons were maintained in Neurobasal medium (Invitrogen) supplemented with 2\% B-27 (Invitrogen) and $0.5 \mathrm{~mm}$ glutamine (Invitrogen). ELISA measurements of both cell media and cell lysates revealed the presence of both GABA and glutamate in the culture (glutamate $=32.2$ $\mu \mathrm{g}, \mathrm{GABA}=13.9 \mu \mathrm{g})$.

DNA constructs, lentivirus preparation, and infection. All shRNAs were cloned in the pLVTHM vector (Addgene), which contains an EF- $1 \alpha$ promoter for target gene expression, using the following oligo DNA pairs as previously described (Liu et al., 2014).

Lenti-shRNA control: 5'-CGCGTCACAGCCCTTCCACCTCCATT CAAGAGATGGAGGTGGAAGGGCTGTGTTTTTTA- ${ }^{\prime}$ and $5^{\prime}$-CGCG TAAAAAACACAGCCCTTCCACCTCCATCTCTTGAATGGAGGTGG AAGGGCTGTGA-3' . Lenti-shATF4: 5' -CGCGTGCCTGACTCTGCTG
CTTATTTCAAGAGAATAAGCAGCAGAGTCAGGCTTTTTTA-3' and 5' -CGCGTAAAAAAGCCTGACTCTGCTGCTTATTCTCTTGAAATA AGCAGCAGAGTCAGGCA-3'.

Lenti-shATF4 addback was generated using the QuikChange Sitedirected Mutagenesis kit (Stratagene). Point mutations were introduced into the Lenti-ATF4 at the recognition site for shATF4 (CCTGACTC TGCTGCTTAT to CCAGAGTCAGCTGCTTAC).

Lenti-shATF4 mut/addback was generated from shATF4addback by introducing point mutations at the DNA binding site (292RYRQKKR298 to 292GYLEAAA298).

Lenti-shCdc42 was generated according to a published siRNA sequence 5'-GAUAACUCACCACUGUCCATT-3' (Deroanne et al., 2005). A scrambled shRNA (lenti-shCdc42scr) was generated by using the following oligo DNA pair: 5'-CGCGTGTCCAACGTCCATATACCATTCAAGAGATGG TATATGGACGTTGGACTTTTTTA-3' and 5' -CGCGTAAAAAAGTCCA ACGTCCATATACCATCTCTTGAATGGTATATGGACGTTGGACA-3'. Lentiviral particles were produced using the second-generation packaging system. Briefly, HEK293T cells were transfected with the respective lentiviral constructs for shRNA together with the packaging vectors psPAX2 and pMD2.G (Addgene) using calcium phosphate. Two and three days after transfection, cell supernatants were collected and lentiviral particles were concentrated $20-30 \times$ by centrifugation in Amicon Ultracentrifugal filters $(100 \mathrm{kDa})$ (Millipore). Viral titer ranged between 1 and $5 \times 10^{6}$ virions $/ \mu \mathrm{l}$. Primary neuronal cultures were infected with viral particles on $7 \mathrm{DIV}$, and RNA and protein extraction was performed at the indicated time points.

$R N A$ extraction and $q R T-P C R$. Total RNA was extracted from rat primary hippocampal cultures 4,8 , and $12 \mathrm{~d}$ after lentiviral infection according to the RNeasy Mini Protocol (QIAGEN). RNA concentration and purity were determined using a NanoDrop 8000 (Thermo Fisher Scientific). mRNA was then reverse-transcribed into cDNA using the first-strand cDNA synthesis system for qRT-PCR (Origene) following the manufacturer's instructions. Reaction mixtures were diluted fivefold and subjected to qRT-PCR amplification (Eppendorf) using FastStart SYBR Green Master mix (Roche). The following primers were used: ATF4: forward 5'-ATGCCAGATGAGCTCTTGACCAC-3' and reverse 5'-GTCATTGTCAGAGGGAGTGTCTTC-3'; $\alpha$-tubulin: forward $5^{\prime}$ TACACCATTGGCAAGGAGAT- $3^{\prime}$ and reverse $5^{\prime}$-GGCTGGGTAAAT GGAGAACT-3; GABA $_{\mathrm{B}} \mathrm{R}$ 1a: forward 5' -CACACCCAGTCGCTGTG-3' and reverse 5'-GAGGTCCCCACCCGTCA-3'; and GABA 5 $_{\mathrm{B}} \mathrm{R} 1 \mathrm{~b} 5^{\prime}$-GG GACCCTGTACCCCGGTG-3' and reverse 5' -GGAGTGAGAGGCCCA CACC- $3^{\prime}$. Relative product quantities for each transcript were performed in triplicate, normalized to $\alpha$-tubulin mRNA as an endogenous control, and determined using the comparative $\mathrm{C}_{\mathrm{T}}$ method.

Electrophysiology. Primary hippocampal neurons (19-21 DIV, 2 weeks after lentiviral infection) were used for tight-seal conventional whole-cell patch clamp. All the currents were recorded from pyramidal-like neurons, based on the their large $(\sim 15 \mu \mathrm{m})$ triangular-shaped somas. Coverslips were placed in a recording chamber with bath solution containing the following (in mM): $119 \mathrm{NaCl}, 5 \mathrm{KCl}, 20 \mathrm{HEPES}, 30$ glucose, $2 \mathrm{CaCl}_{2}$, $2 \mathrm{MgCl}_{2}$. The $\mathrm{pH}$ and osmolarity of the bath solution were adjusted to 7.3 and $330 \mathrm{mOsm} / \mathrm{L}$, respectively. For spontaneous action potential recordings, glass pipettes were filled with intracellular electrode solution, $\mathrm{pH}$ $7.3(285 \mathrm{mOsm} / \mathrm{L})$ containing the following (in $\mathrm{mm})$ : $130 \mathrm{~K}$-gluconate, $10 \mathrm{KCl}, 10 \mathrm{HEPES}, 1 \mathrm{MgCl}_{2}, 0.06 \mathrm{CaCl}_{2}, 0.1$ EGTA, $3 \mathrm{MgATP}, 0.3$ $\mathrm{Na}_{2} \mathrm{GTP}$, and typically registered $4-8 \mathrm{M} \Omega$ pipette resistances. Following acquisition of electrical access, cells were held in current-clamp mode at $\mathrm{I}=0$. For mIPSC experiments, glass pipettes were filled with intracellular electrode solution, pH $7.3(285 \mathrm{mOsm} / \mathrm{L})$, containing the following (in mM): $130 \mathrm{KCl}, 10$ HEPES, $0.5 \mathrm{CaCl}_{2}$, 1 EGTA, $3 \mathrm{MgATP}, 0.3 \mathrm{Na}_{2} \mathrm{GTP}$. Furthermore, $1 \mu \mathrm{M}$ TTX, $10 \mu \mathrm{M}$ CNQX, and $50 \mu \mathrm{M}$ D-APV were continuously perfused during the experiment. All the cells were recorded at $-70 \mathrm{mV}$ for $10 \mathrm{~min}$, and a $5 \mathrm{mV}$ hyperpolarizing test pulse was applied periodically during recordings to ensure that the access resistance did not change significantly and was $<25 \mathrm{M} \Omega$. If not, the recordings were discarded. Signals were filtered at $2 \mathrm{kHz}$, digitized at $10 \mathrm{kHz}$, stored and analyzed offline using MiniAnalysis Software (Synaptosoft, version 6.0.7). The threshold for event detection was set at $5 \mathrm{pA}$. Recordings were performed at room temperature under constant perfusion $(2 \mathrm{ml} / \mathrm{min})$ and acquired using Clampex software and a microamplifier (Multi- 
Clamp 700B, Molecular Devices). For baclofen-induced GIRK currents, hippocampal neurons were bathed initially with a solution containing the following (in mM): $119 \mathrm{NaCl}, 5 \mathrm{KCl}, 20 \mathrm{HEPES}, 30$ glucose, $2 \mathrm{CaCl}_{2}$, $2 \mathrm{MgCl}_{2}, \mathrm{pH} 7.3$ (330 mOsm/L), and then switched to a high potassium solution $(\mathrm{hK})$ containing the following (in $\mathrm{mm}$ ): $85 \mathrm{NaCl}, 60 \mathrm{KCl}, 2$ $\mathrm{MgCl}_{2}, 2 \mathrm{CaCl}_{2}, 10$ HEPES, 10 glucose, $\mathrm{pH} 7.3$, to determine the amplitude of the basal potassium current. When the basal current reached equilibrium, baclofen diluted in hK was applied. The hK-induced current was subtracted from the total current to obtain the baclofen-induced GIRK current. Membrane potential was held at $-70 \mathrm{mV}$ throughout the duration of the experiment.

Surface and total protein isolation. Membrane-bound and total protein isolation was conducted using the EZ-Link NHS-PEO4-Biotinylation Kit (Pierce), following the manufacturer's instructions. Briefly, cells were gently washed three times with ice-cold PBS containing $1 \mathrm{mM} \mathrm{MgCl}_{2}$ and $0.1 \mathrm{mM} \mathrm{CaCl}_{2}(\mathrm{PBS} / \mathrm{CM})$ and then incubated with $500 \mu \mathrm{g} / \mathrm{ml}$ of EZ-link NHS-PEO4-biotin dissolved in ice-cold PBS at $4^{\circ} \mathrm{C}$ for $1 \mathrm{~h}$. Cells were then washed once with ice-cold PBS, and the reaction quenched by adding $500 \mu \mathrm{l}$ of $100 \mathrm{~mm}$ glycine for $10 \mathrm{~min}$, followed by 3 washes in ice-cold PBS. Cells were then harvested in RIPA buffer supplemented with protease/phosphatase inhibitor and centrifuged at 14,000 rpm for $15 \mathrm{~min}$ at $4^{\circ} \mathrm{C} ; 30 \mu \mathrm{l}$ of the resulting supernatant was collected for total protein input and the rest incubated with $50 \mu \mathrm{g}$ of streptavidin beads, rotating overnight at $4^{\circ} \mathrm{C}$. Beads were washed 5 times with RIPA buffer and bound proteins eluted with $1 \times$ sample buffer by boiling for $5 \mathrm{~min}$.

Immunoblotting. After adding NuPAGE LDS Sample Buffer (Invitrogen) and $5 \% \beta$-mercaptoethanol, samples were boiled for $15 \mathrm{~min}$ and proteins were separated by electrophoresis on $4 \%-12 \%$ BisTris SDSacrylamide gels (Invitrogen). After transfer, the membranes were blocked for $1 \mathrm{~h}$ at room temperature with 5\% milk and then incubated overnight with primary antibody. The following primary antibodies were used: rabbit anti-GABA ${ }_{B}$ R1 (1:1000, Abcam, \#55051) (Zapata et al., 2017), GABA $_{B}$ R2 (1:1000, Cell Signaling Technology, \#3839), rabbit anti-GABA $A_{A} R \quad$ (1:1000, Synaptic Systems, \#224803), rabbit antiGABA $_{A}$ R $\gamma 2$ (1:1000, Synaptic Systems, \#224003), rabbit anti-ATF4 (1: 1000, Cell Signaling Technology, \#11815), rabbit anti-Cdc42 (1:1000, Cell Signaling Technology, \#2462S), rabbit anti-GIRK1 (1:500, Abcam, \#129182), rabbit anti-GIRK2 (1:200, Sigma-Aldrich, \#P8122), rabbit anti-GIRK3 (1:400, Sigma-Aldrich, \#P8247), mouse anti-GAPDH (1: 10,000, Invitrogen, \#MA1-16757), rabbit anti- $\mathrm{K}_{\mathrm{v}} 1.1$ (1:400, SigmaAldrich, \#P8247), mouse anti-K 2.1 (1:500, Abcam, \#ab192761), rabbit anti-K $\mathrm{K}_{\mathrm{v}} 4.2$ (1:200, Sigma; Millipore, \#07-491), and rabbit anti-Ca 2.1 (1:500, Abcam, \#ab32642). Densitometric quantification of the bands was performed using ImageJ software (National Institutes of Health). Total level of proteins (input) was normalized to GAPDH, whereas membrane-bound samples were normalized with the ratio input/ GAPDH. GAPDH was undetectable in the membrane-bound fraction, therefore excluding the possibility that the membrane was leaky or compromised.

Statistical analysis. Data are shown as mean \pm SEM. Comparison between two groups was performed with a two-tailed unpaired Student's $t$ test. Comparison between multiple groups was performed using twoway ANOVA, followed by a Bonferroni post hoc test when applicable. Statistical significance was set at $p<0.05$.

\section{Results}

\section{ATF4 knockdown increases neuronal excitability}

We previously described a key role for ATF4 in modulating glutamatergic neurotransmission both in vitro and in vivo and in regulating dendritic spines (Liu et al., 2014; Pasini et al., 2015). Given the pivotal roles of these two aspects in controlling the excitability properties of neurons, we next set out to directly investigate the role of ATF4 in intrinsic neuronal excitability. For this purpose, we used lentivirally delivered shRNAs to specifically downregulate ATF4 expression in 7 DIV cultured rat hippocampal neurons and performed whole-cell patch clamp 2 weeks after the infection to record the frequency of spontaneously occurring action potentials (sAPs). At this time in culture (3 weeks total), the neurons have formed extensive synaptic connections (Liu et al., 2014). As shown in Figure $1 A, B$, knockdown of ATF4 resulted in an $\sim 3$-fold increase in the frequency of sAPs compared with neurons infected with a control shRNA $(\operatorname{shCtrl}=0.35 \pm 0.07 \mathrm{~Hz}$, shATF $4=1.11 \pm 0.26 \mathrm{~Hz}$; post hoc Bonferroni, shCtrl vs shATF4, $p<0.01)$ To confirm that this result was not due to off-target effects, we performed a rescue experiment in which the neurons were coinfected with lentiviruses expressing shATF4 and an ATF4 construct (ATF4add) conservatively mutated to make it unresponsive to shATF4. This resulted in knockdown of endogenous and overexpression of exogenous ATF4, respectively (Liu et al., 2014). Our results indicate that ATF4add restored the firing rate to the control level (Fig. 1A; shATF4+ATF4add $=0.46 \pm$ $0.07 \mathrm{~Hz}$; post hoc Bonferroni, shCtrl vs shATF4+ATF4add, $p>$ 0.05). However, while ATF4 over-expression rescued the firing rate, it did not reduce it below that seen in control cultures. Next, to test whether the effects of ATF4 on SAP frequency requires its transcriptional activity, we co-infected cultured hippocampal neurons with shATF4 and a mutant ATF4 construct, ATF4add/ mut, that is not recognized by shATF4 and that encodes a mutant ATF4 that does not bind DNA and thus is transcriptionally inactive. This results in knockdown of endogenous ATF4 and overexpression of inactive exogenous ATF4 (Liu et al., 2014). In contrast to ATF4add, ATF4add/mut failed to rescue the effect of ATF4 knockdown (Fig. 1A; shATF4+ATF4add/mut $=1.17 \pm$ $0.21 \mathrm{~Hz}$; post hoc Bonferroni, shCtrl vs shATF4+ATF4add/mut, $p<0.01$ ), suggesting that ATF4 must retain its transcriptional capability to regulate the frequency of neuronal firing. Because APs are generated by voltage-gated sodium $(\mathrm{NaV})$ and potassium (KV) channels (Bean, 2007), we investigated whether ATF4 down-regulation could affect the neuronal firing rate by influencing these major AP constituents. However, our results show no differences in either $\mathrm{NaV}$ or $\mathrm{KV} \mathrm{I}-\mathrm{V}$ curves obtained from shCtrl- or shATF4-infected hippocampal cultures (Fig. 1B-D), suggesting that ATF4 regulates neuronal excitability by a mechanism independent of effects on Nav or Kv.

\section{ATF4 regulates trafficking of $\mathrm{GABA}_{\mathrm{B}}$ Rs to the membrane}

Among the many proteins reported to modulate the excitability of neurons, we focused on $\mathrm{GABA}_{B} \mathrm{Rs}$, the metabotropic ( $\mathrm{G}$ protein coupled) receptors for GABA. Postsynaptic $G_{A B A} R s$ induce a slow IPSC by gating Kir-type $\mathrm{K}^{+}$channels. This in turn hyperpolarizes the membrane and shunts excitatory currents, thereby inhibiting generation of action potentials (Leung and Peloquin, 2006). In this light, we confirmed that blocking $\mathrm{GABA}_{\mathrm{B}} \mathrm{R}$ activity in our cultures increases the neuronal firing rate. As shown in Figure $2 A$, application of the specific $G_{A B A} R$ antagonist CGP55845 $(10 \mu \mathrm{M})$ produced a rapid eightfold rise (from $\sim 0.4$ to $3.2 \mathrm{~Hz}$ ) of sAP frequency. Of potential relevance, ATF4 has been reported to directly bind $\mathrm{GABA}_{\mathrm{B}}$ Rs as well as to differentially regulate promoter activity of the subunits $1 \mathrm{a}$ and $1 \mathrm{~b}$ of $\mathrm{GABA}_{\mathrm{B}} \mathrm{Rs}$ (Steiger et al., 2004). We therefore first investigated whether ATF4 downregulation affects expression of $\mathrm{GABA}_{\mathrm{B}} \mathrm{Rs}$ at the transcriptional level. To achieve this, we infected cultured hippocampal neurons with either shATF4 or shCtrl for 4-15d and then performed qRT-PCR. As shown in Figure 2B, knockdown of ATF4 did not significantly affect the transcript levels of either $\mathrm{GABA}_{\mathrm{B}} \mathrm{R} 1 \mathrm{a}$ or $1 \mathrm{~b}$ subunits $(\mathrm{ATF} 4,4 \mathrm{~d}$ : shCtrl $=100 \pm$ $7.1 \%$, shATF $4=19.1 \pm 2.4 \%, t$ test, $p<0.01$; ATF $4,8 \mathrm{~d}: \operatorname{shCtrl}=$ $100 \pm 3 \%$, shATF $4=11.6 \pm 2.8 \%, t$ test, $p<0.01$; ATF $4,12 \mathrm{~d}$ : $\operatorname{shCtrl}=100 \pm 4.19 \%$, shATF $4=9.47 \pm 1.63 \%, t$ test,$p<0.01$.

Next, we determined whether knocking down ATF4 would alter total or membrane-bound protein expression of $G_{A B A} R$ Rs. 
A

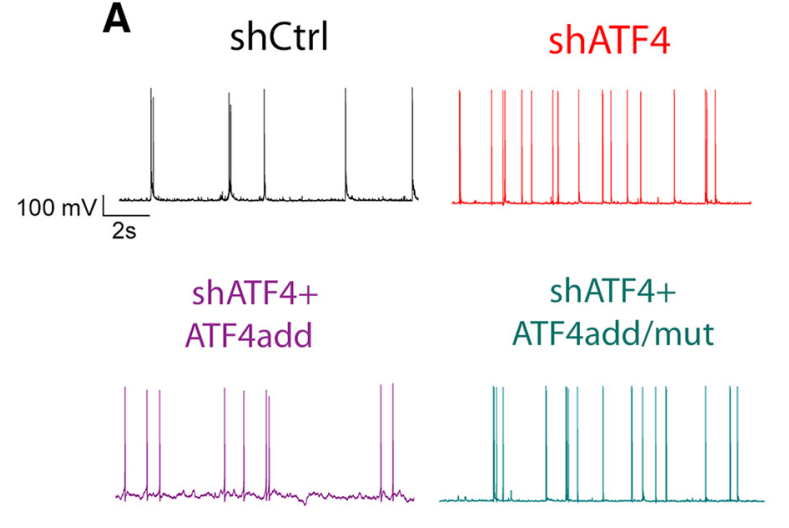

- shCtrl

- shATF4

shATF4+ATF4add

shATF4+ATF4add/mut

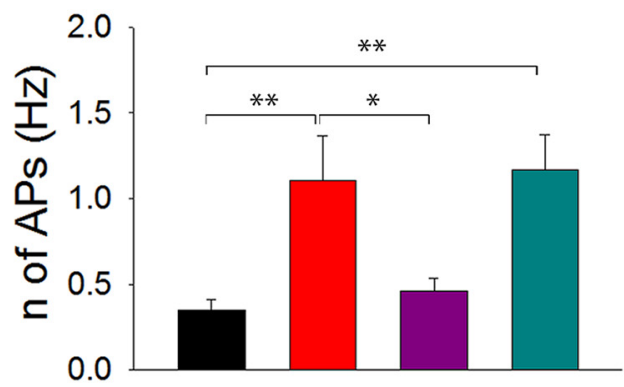

B

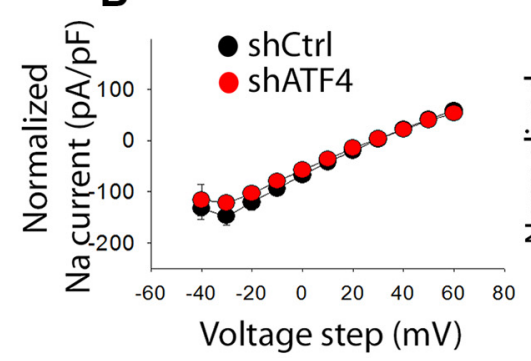

C

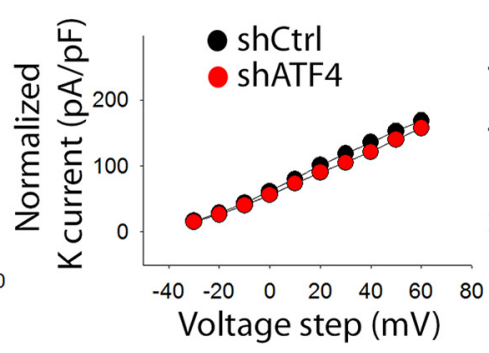

D

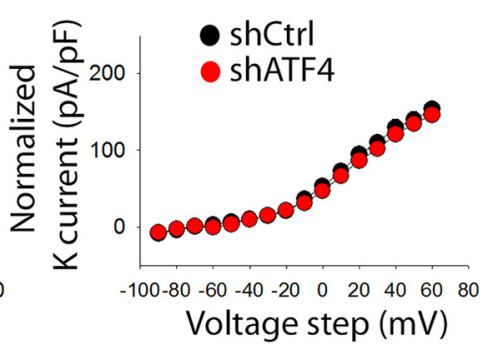

Figure 1. ATF4 knockdown increases neuronal excitability. $A$, The frequency of spontaneously-occurring action potentials (sAPs) is increased upon ATF4 down-regulation; this effect appears to be mediated by ATF4's transcriptional capability. Left panel, representative traces of sAPs recorded from cultured hippocampal neurons infected at DIV7 for 2 weeks with lentivirus expressing either shCtrl (black trace), shATF4 (red trace), shATF4+ ATF4add (purple trace), or shATF4 + ATF4add/mut (cyan trace). Right panel, summary bar graph showing the mean frequencies ( \pm SEM) of sAPs of hippocampal neurons infected with shCtrl (black bars, $n=24$ ), shATF4 (red bars, $n=22$ ), shATF4+ATF4add (purple bars, $n=18$ ), shATF4+ATF4add/mut (cyan bars, $n=18$ ) constructs. $\boldsymbol{B}$ - $\boldsymbol{D}$, ATF4 down-regulation does not affect $\mathrm{Na}^{2+}$ and $\mathrm{K}^{+}$voltage-gated channels in shATF4-infected neurons (red dots) when compared to shCtrl neurons (black dots). $\boldsymbol{B}$, Voltage-gated Na ${ }^{2+}$ currents were evoked by $1 \mathrm{~s} \mathrm{step} \mathrm{depolarizations} \mathrm{from}-40$ to $+60 \mathrm{mV}$ with $10-\mathrm{mV}$ increments ( $\mathrm{sh}(\mathrm{trl} n=15$; shATF $4 n=16)$. C, A-type $\mathrm{K}+$ currents were evoked by $1 \mathrm{~s}$ step depolarizations from -30 to $+60 \mathrm{mV}$, with 10-mV increments (shCtrl $n=29$; shATF4 $n=33$ ), and successively isolated. D, Delayed-rectifying $\mathrm{K}^{+}$currents were evoked by $1 \mathrm{~s} \mathrm{step} \mathrm{depolarizations} \mathrm{from}-90$ to $+60 \mathrm{mV}$, with $10 \mathrm{mV}$ increments ( $\operatorname{shCtrl} n=30$; shATF $4 n=34$ ), and successively isolated. Values are expressed as mean \pm SEM. ${ }^{*} p<0.05 ;{ }^{* *} p<0.01$.

To achieve this, we performed biotinylation of plasma membrane proteins on cultured hippocampal neurons with or without ATF4 knockdown (infected at 7 DIV for 2 weeks), isolated the biotinylated proteins on streptavidin-bound beads, and performed Western immunoblotting analysis for $\mathrm{GABA}_{\mathrm{B}} \mathrm{R}$ subunits 1a and $1 \mathrm{~b}$ on both the input (total cell lysate) and membrane fractions. Densitometric quantification from multiple experiments showed that ATF4 downregulation did not affect total $\mathrm{GABA}_{\mathrm{B}} \mathrm{R} 1 \mathrm{a}$ and $1 \mathrm{~b}$ protein levels (Fig. 2C) but significantly decreased the levels of $\mathrm{GABA}_{\mathrm{B}} \mathrm{R}$ subunits $1 \mathrm{a}$ and $1 \mathrm{~b}$ in the biotinylated membrane fraction (Fig. $2 C ; \mathrm{GABA}_{\mathrm{B}} \mathrm{R}$ 1a: shCtrl $=100 \pm 11.8 \%$, shATF4 $=$ $46.7 \pm 10.7 \%$; post hoc Bonferroni test: shCtrl vs shATF4, $p<$ $0.01 ; \mathrm{GABA}_{\mathrm{B}} \mathrm{R} 1 \mathrm{~b}: \operatorname{shCtrl}=100 \pm 7.2 \%$, shATF $4=48.2 \pm 7.9 \%$; post hoc Bonferroni test: shCtrl vs shATF4, $p<0.01$ ), thus indicating a role for ATF4 in regulating $\mathrm{GABA}_{\mathrm{B}} \mathrm{R}$ trafficking, but not overall expression.

To address the question of whether the effect of ATF4 on membrane trafficking of $\mathrm{GABA}_{\mathrm{B}}$ Rs involves ATF4's transcriptional activity, we performed a rescue experiment as above and found that ATF4add/mut, in contrast to ATF4add, failed to reverse the effects of ATF4 knockdown (Fig. $2 C ; \mathrm{GABA}_{\mathrm{B}} \mathrm{R}$ 1a, shATF4 + ATF4add $=95.1 \pm 10.3 \%$, shATF4 + ATF4add $/$ mut $=$ $39.8 \pm 8.2 \%$; post hoc Bonferroni test: shCtrl vs shATF4+ ATF4add, $p>0.05$; shATF4 vs shATF4+ATF4add, $p<0.05$; shCtrl vs shATF4+ATF4add/mut, $p<0.01 ; \mathrm{GABA}_{\mathrm{B}} \mathrm{R} 1 \mathrm{~b}$, shATF4+ATF4add $=110.5 \pm 12.7 \%$, shATF4+ATF4add $/$ mut $=55.2 \pm 10 \%$; post hoc Bonferroni test: shCtrl vs shATF $4+$
ATF4add, $p>0.05$; shATF4 vs shATF4+ATF4add, $p<0.001$; shCtrl vs shATF4+ATF4add/mut, $p<0.05$ ). This indicates, as with neuronal excitability, that ATF4 has a transcriptional role in regulating trafficking of $\mathrm{GABA}_{\mathrm{B}} \mathrm{Rs}$. The data also show, as with excitability, that ATF4 overexpression is not sufficient to drive surface expression of $\mathrm{GABA}_{B}$ Rs beyond that seen with basal endogenous expression.

We next asked whether knocking down ATF4 might produce a more general or nonspecific effect on membrane proteins. Interestingly, both the total and membrane-bound levels of $\mathrm{GABA}_{\mathrm{B}} \mathrm{R} 2$ (biotin labeled as above) were unaffected by ATF4 downregulation (Fig. 2D). We also examined the effect of shATF4 on membrane-exposed $\beta 2$ and $\gamma 2$ subunits of $\mathrm{GABA}_{\mathrm{A}}$ receptors and found no effects on either the total or membraneexposed protein levels (Fig. $3 A$ ). In addition to $\mathrm{GABA}_{B} \mathrm{Rs}$, a wide variety of voltage-sensitive $\mathrm{K}$ and $\mathrm{Ca}$ channels has been described to regulate excitability properties of neurons (Chen et al., 2006; Hsiao et al., 2009; Rossignol et al., 2013; Speca et al., 2014). We therefore queried whether the effect of ATF4 on neuronal excitability was in part due to its capability to regulate the expression or localization of $\mathrm{K}_{\mathrm{v}} 1.1, \mathrm{~K}_{\mathrm{v}} 2.1, \mathrm{~K}_{\mathrm{v}} 4.2$, and $\mathrm{Ca}_{\mathrm{v}} 2.1$. As shown in Figure $3 B-E$, neither the total nor the membrane-bound levels of these proteins were affected by ATF4 downregulation. These findings thus indicate that ATF4 has a selective role in regulation of membrane-bound proteins involved in neuronal excitability and that this includes $\mathrm{GABA}_{\mathrm{B}} \mathrm{Rs}$. 

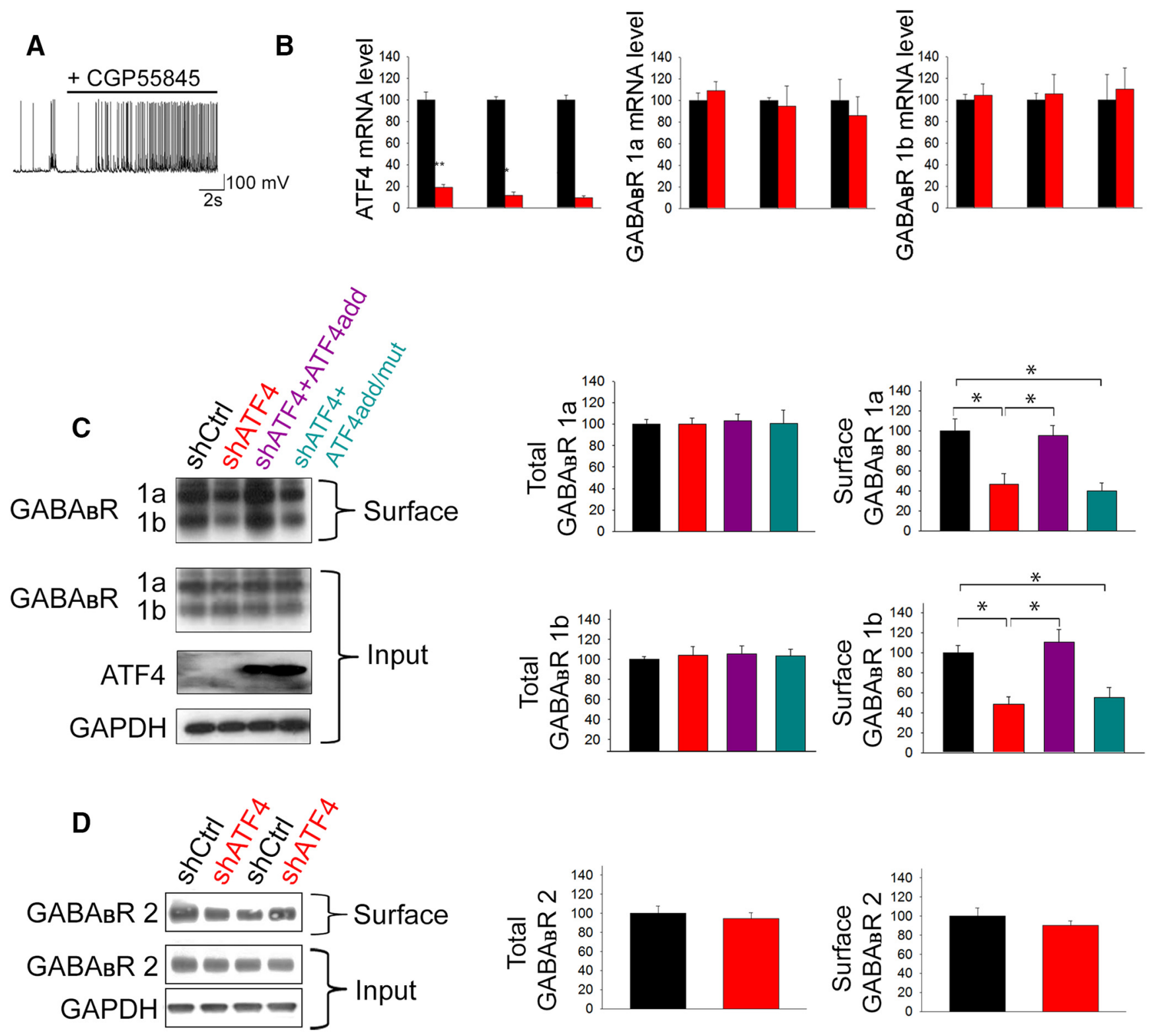

Figure 2. ATF4 regulates $G A B A_{B} R$ surface expression. $A, G A B A_{B} R$ blockade increases the frequency of $s A P s$ in control neurons. Representative trace of $s A P s$ recorded from cultured hippocampal neurons infected with shCtrl-carrying lentivirus treated with the specific $G_{A B A_{B} R}$ antagonist CGP55845 (10 $\left.\mu \mathrm{m}\right)$. $B$, Time course experiment showing no changes in the mRNA levels for GABA ${ }_{B} R$ subunits $1 \mathrm{a}$ and $1 \mathrm{~b}$ upon ATF4 downregulation. Bar graphs represent $\mathrm{qPCR}$ analysis of $A T F 4$ (left), $G_{A B A_{B} R} 1 \mathrm{a}$ (middle), and $\mathrm{GABA}_{B} \mathrm{R} 1 \mathrm{~b}$ (right) mRNA levels extracted 4,8 , and $12 \mathrm{~d}$ after infection with lentivirus carrying either shCtrl (black bars) or shATF4 (red bars) constructs. Data are mean \pm SEM from three independent experiments. C, ATF4 downregulation decreases membrane levels of $G_{B B} A_{B}$. The 7 DIV hippocampal cultured neurons were infected with indicated lentiviral constructs (black represents shCtrl; red represents shATF4; purple represents shATF4+ATF4add; cyan represents shATF4+ATF4add/mut) for $14 \mathrm{~d}$ before undergoing extraction of total and membrane proteins. Left, Representative Western immunoblot. Right, Bar graphs represent densitometric analysis of total (left) or membrane (right) $G_{A B A} R$ 1a and 1b protein normalized to GAPDH. D, ATF4 downregulation does not affect total or surface levels of GABA $B$ R . Left, Representative Western immunoblot. Right, Bar graphs represent densitometric analysis of total (left) or membrane (right) $G_{A B A} R 2$ protein normalized to GAPDH. Data are mean \pm SEM from three independent experiments. ${ }^{*} p<0.05 ;{ }^{* *} p<0.01$.

\section{ATF4 knockdown reduces GIRK currents}

We next queried whether the reduction we observed in the number of membrane-inserted $\mathrm{GABA}_{\mathrm{B}} \mathrm{Rs}$ after ATF4 downregulation reflected a change in the functionality of the receptors themselves. Postsynaptic $\mathrm{GABA}_{\mathrm{B}} \mathrm{Rs}$ are associated with, and mediate part of their functions through, GIRK channels (Gassmann and Bettler, 2012). We therefore studied the function of $\mathrm{GABA}_{B} \mathrm{Rs}$ by whole-cell patch-clamp recording of $G_{A B A} R$-induced $\mathrm{K}^{+}$ GIRK currents in 7 DIV hippocampal cultured neurons infected for 2 weeks with lentiviruses carrying either shCtrl or shATF4. As shown in Figure 4A, we first calibrated our recordings by applying the $\mathrm{GABA}_{\mathrm{B}} \mathrm{R}$ agonist baclofen $(100 \mu \mathrm{M})$, which elicited sus- tained $\mathrm{K}^{+}$currents in control neurons that were prevented by pretreating the cells with a specific $\mathrm{GABA}_{\mathrm{B}} \mathrm{R}$ antagonist (SCH50911, $100 \mu \mathrm{M}$ ). Consistent with our finding that ATF4 downregulation reduces cell surface $G_{A B A} R$ levels, when we recorded baclofen-induced GIRK currents in ATF4 knockdown neurons, we found them to be significantly reduced compared with those in ShCtrl-infected neurons (Fig. 4B; shCrl $725.9 \pm 58.4 \mathrm{pA}$, shATF $435.1 \pm 39.2 \mathrm{pA}$; post hoc Bonferroni, $p<0.01$ ). This effect did not appear to be mediated by effects on GIRK channels in that shATF4 did not affect total or membrane-bound GIRK1, GIRK2, or GIRK3 protein levels (Fig. 4C). Finally, ATF4add, but not ATF4add/mut, com- 

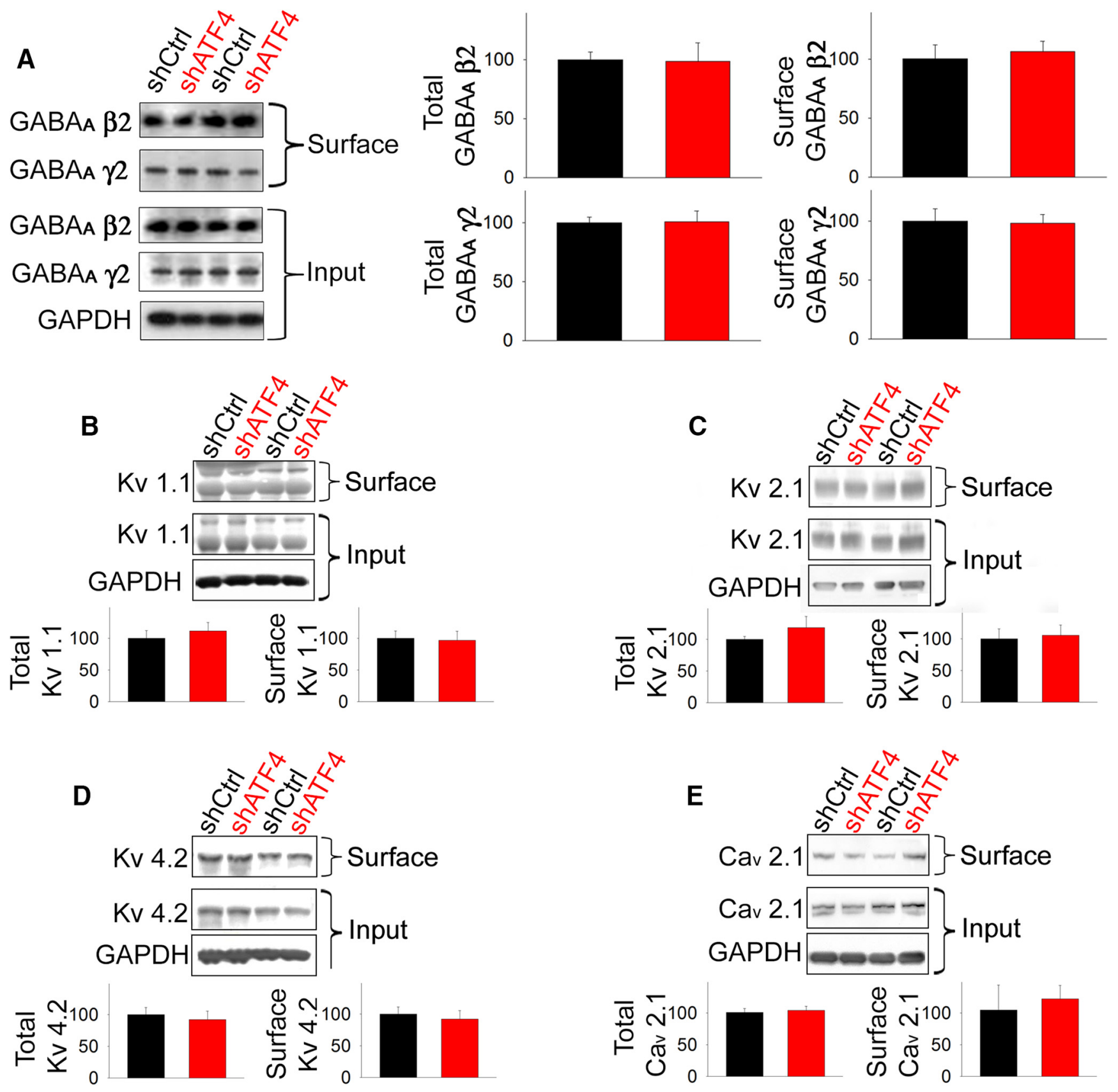

Figure 3. ATF4 downregulation does not affect total and membrane levels of $G_{A B A}$ Rs and voltage-sensitive $K$ or Ca channels. DIV 7 cultured hippocampal neurons were infected with indicated lentiviral constructs (black represents shCtrl; red represents shATF4) for $14 \mathrm{~d}$ before undergoing extraction of total and membrane proteins. $A$, Left, Representative Western immunoblot. Bar graphs represent densitometric analysis of total (left) or membrane (right) $G_{A B A} R \beta 2$ and $\gamma 2$ protein normalized to GAPDH. $\boldsymbol{B}$, Top, Representative Western immunoblot. Bar graphs represent densitometric analysis of total (left) or membrane (right) $\mathrm{K}_{\mathrm{v}} 1.1$ protein normalized to GAPDH. C, Top, Representative Western immunoblot. Bar graphs represent densitometric analysis of total (left) or membrane (right) $K_{v} 2.1$ protein normalized to GAPDH. D, Top, Representative Western immunoblot. Bar graphs represent densitometric analysis of total (left) or membrane (right) $K_{v} 4.2$ protein normalized to GAPDH. $\boldsymbol{E}$, Top, Representative Western immunoblot. Bar graphs represent densitometric analysis of total (left) or membrane (right) Ca 2.1 protein normalized to GAPDH. Data are mean \pm SEM from three independent experiments, each run in duplicate. The differences between shCtrl and shATF4 were not significant $(p>0.05)$ in all cases.

pletely restored the currents to the control level (Fig. $4 B$; shATF4 + ATF4add $=786.9 \pm 69.2 \mathrm{pA}$, shATF4+ATF4add $/$ mut $=545.9 \pm 43.8 \mathrm{pA}$; post hoc Bonferroni: shATF4 vs shATF4+ATF4add, $p<0.001 ;$ shATF4add vs shATF4add/ mut, $p<0.01$ ), further confirming the idea that ATF4 needs to retain its transcriptional capability to regulate the trafficking of $\mathrm{GABA}_{\mathrm{B}}$ Rs. As with $\mathrm{GABA}_{\mathrm{B}} \mathrm{R}$ membrane trafficking, ATF4 overexpression did not raise GIRK current amplitude beyond that in control cultures.
ATF4 knockdown increases the frequency, but not amplitude, of mIPSCs

Given that $\mathrm{GABA}_{\mathrm{B}} \mathrm{R}$ manipulations have been reported to affect the frequency, but not the amplitude of spontaneous mIPSCs (Ulrich and Huguenard, 1996; Kubota et al., 2003; Kirmse and Kirischuk, 2006), we assessed mIPSCs (confirmed by picrotoxin blockade) in cultured hippocampal neurons infected with either shCtrl or shATF4 as a further readout of $\mathrm{GABA}_{\mathrm{B}} \mathrm{R}$ functionality. As shown in Figure 5A, we found that shAT4 significantly in- 

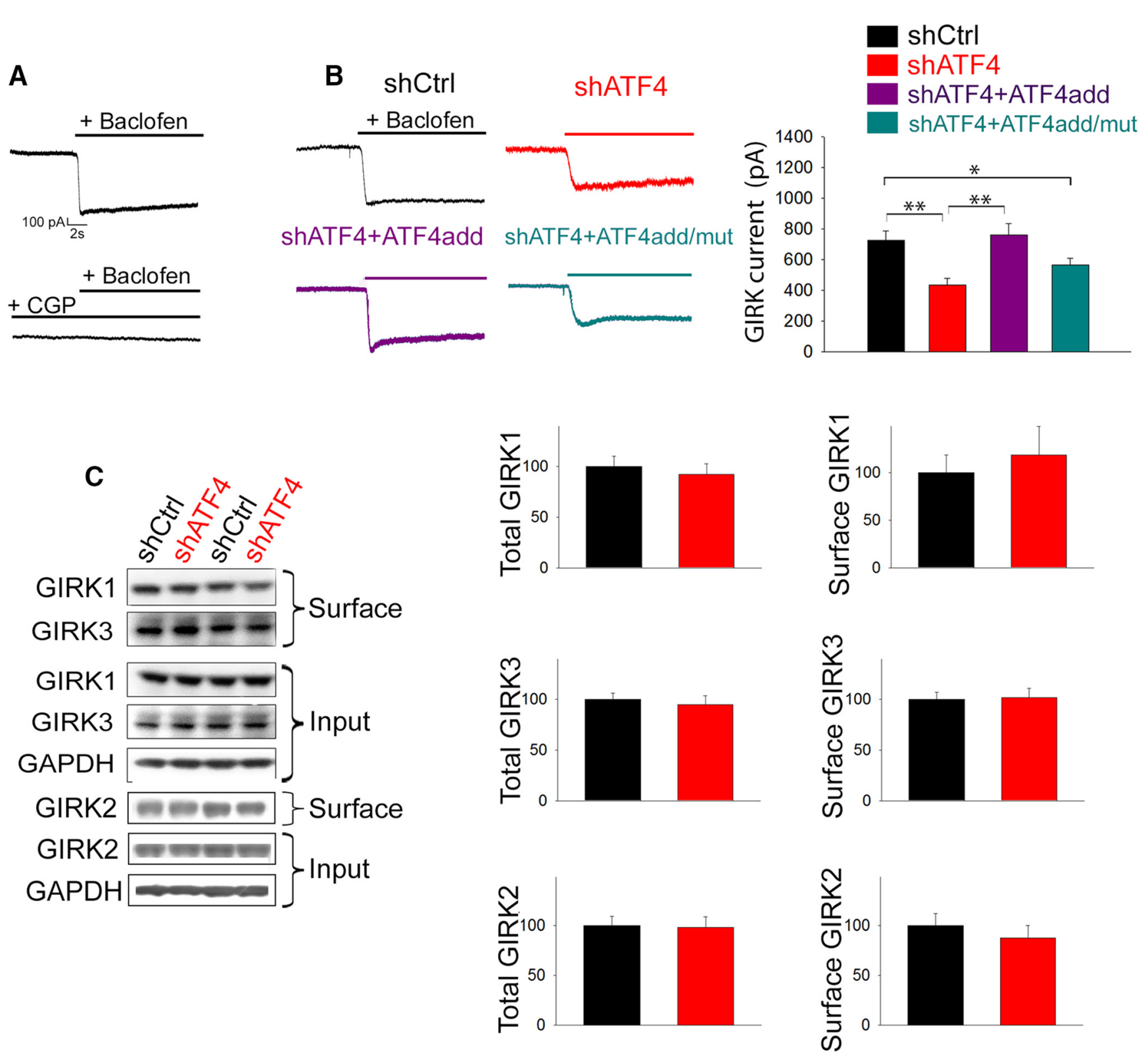

Figure 4. ATF4 knockdown reduces $G A B A_{B} R$-induced GIRK currents. $A$, Specific $G A B A_{B} R$ agonist baclofen ( $100 \mu \mathrm{m}$ ) elicited a sustained GIRK current in cultured hippocampal neurons infected with shCtrl lentivirus. Top, Representative trace. This effect is abolished by pretreating the culture with the specific GABA ${ }_{B} R$ antagonist (GP55845 (10 $\mu \mathrm{m}$; bottom). $B$, shATF4 infection reduces baclofen-induced GIRK currents; this effect is dependent on ATF4's transcriptional capability. Left, Representative traces of baclofen-elicited currents recorded from 7 DIV cultured hippocampal neurons infected for 2 weeks with lentivirus expressing shCtrl (black), shATF4 (red), shATF4+ATF4add (purple), or shATF4+ ATF4add/mut (cyan). Right, Bar graphs represent measurements of the currents (shCtrl, $n=37$; shATF4, $n=39 ;$ shATF4+ATF4add, $n=36$; shATF4+ATF4add/mut, $n=51$ ). Data are mean \pm SEM. ${ }^{*} p<0.05 ;{ }^{* *} p<0.005$. C, ATF4 downregulation does not affect total and membrane levels of GIRK proteins; 7 DIV cultured hippocampal neurons were infected with indicated lentiviral constructs (black represents shCtrl; red represents shATF4) for $14 \mathrm{~d}$ before undergoing extraction of total and membrane proteins. Left, Representative Western immunoblot. Bar graphs represent densitometric analysis of total (left) or membrane (right) GIRK proteins normalized to GAPDH. Data are mean \pm SEM from three independent experiments. ${ }^{*} p<0.05 ;{ }^{* *} p<0.01$.

creases (by $\sim 2$-fold) the frequency, but not the amplitude of mIPSCs (mIPSC frequency: $\operatorname{shCtrl}=1.65 \pm 0.21 \mathrm{~Hz}$, shATF $4=$ $3.43 \pm 0.41 \mathrm{~Hz}$; post hoc Bonferroni: $p<0.05$ ). In addition, adding back ATF4 completely restored the frequency of mIPSCs to control values (Fig. $5 A$; shATF4+ATF4add $=1.19 \pm 0.37 \mathrm{~Hz}$; post hoc Bonferroni: shATF4 vs shATF4+ATF4add, $p<0.05)$. As with other properties described above, ATF4add overexpression did not increase mIPSC frequency beyond the level observed in control cultures. Furthermore, our whole-cell patch-clamp recordings showed that, unlike ATF4add, ATF4add/mut was unable to reverse the effect of ATF4 downregulation on mIPSC frequency (Fig. $5 A$; shATF $4+$ ATF4add/mut $=3.83 \pm 0.76 \mathrm{~Hz}$; post hoc Bonferroni: shCtrl vs shATF4+ATF4add/mut, $p<0.01$ ), confirming that the transcriptional activity of ATF4 is required for this action. To further confirm the idea that membranebound $\mathrm{GABA}_{\mathrm{B}}$ Rs are reduced by shATF4, we treated both shCtrl and shATF4-infected neurons with the specific $\mathrm{GABA}_{\mathrm{B}} \mathrm{R}$ agonist baclofen $(20 \mu \mathrm{M})$ or $\mathrm{GABA}_{\mathrm{B}} \mathrm{R}$ antagonists $\mathrm{SCH} 50911$ and CGP55845 (used at 100 and $10 \mu \mathrm{M}$, respectively). As shown in Figure $5 B$, baclofen application significantly reduced the frequency of mIPSCs both in shCtrl- and shATF4-infected hippocampal neurons $(\operatorname{shCtrl}+$ baclofen $=0.79 \pm 0.14 \mathrm{~Hz}$, shATF4+ baclofen $=1.23 \pm 0.15 \mathrm{~Hz}$; post hoc Bonferroni: shCtrl vs shCtrl+baclofen, $p<0.05$; shATF4 vs shATF4+ baclofen, $p<$ 
A

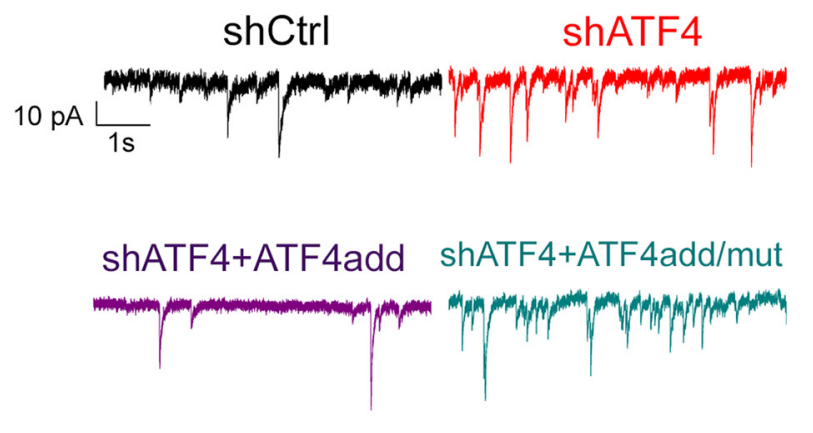

B
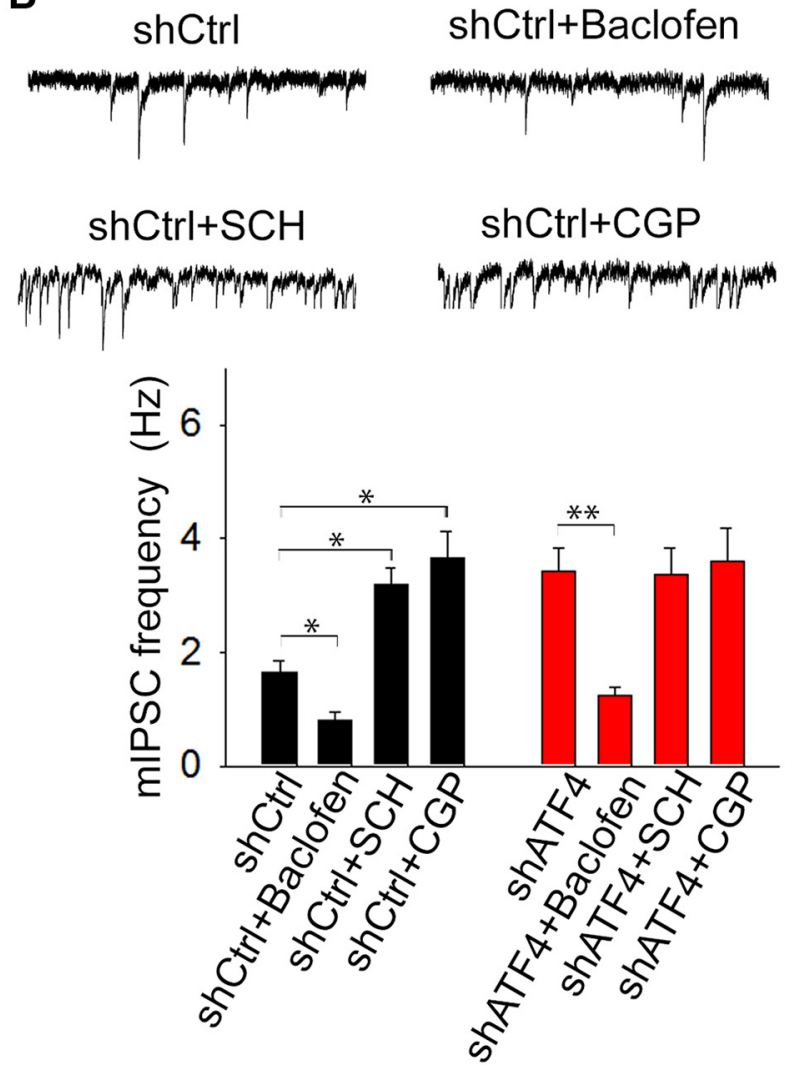

shCtrl+Baclofen

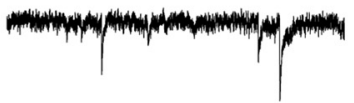

shCtrl+CGP
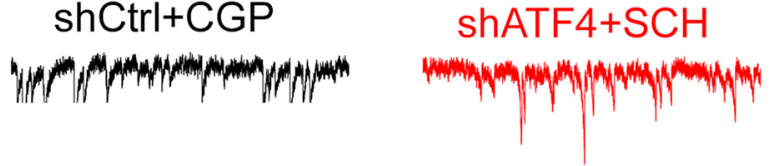

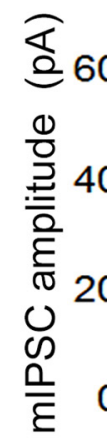

ShATF4

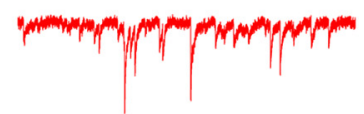

shCtrl

shATF4

shATF4+ATF4add

shATF4+ATF4add/mut
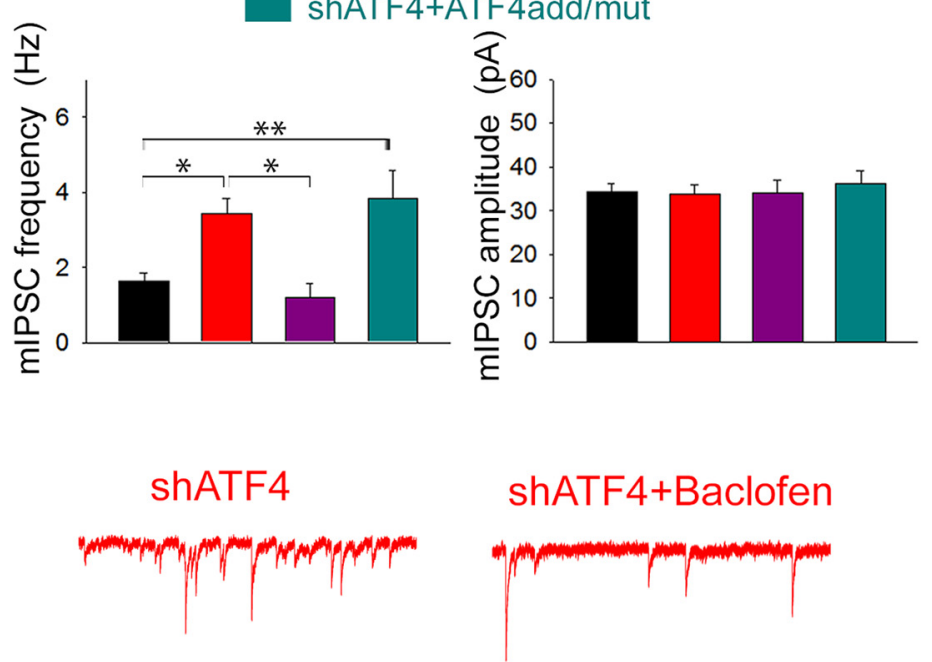

shATF4+CGP

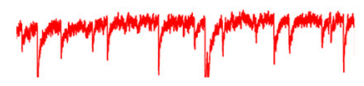

Figure 5. ATF4 knockdown increases the frequency, but not amplitude, of mIPSCS. $A$, Left, Representative mIPSC traces recorded from 7 DIV hippocampal neurons infected for 2 weeks with lentivirus expressing shCtrl (black), shATF4 (red), shATF4+ ATF4add (purple), or shATF4+ATF4add/mut (cyan). Right, Bar graphs represent the frequency (left) and the amplitude (right) of mIPSCs

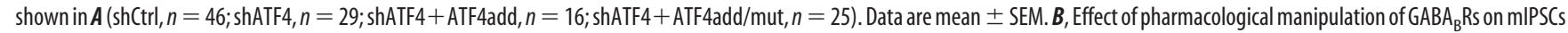
recorded from 7 DIV hippocampal neurons infected for 2 weeks with lentivirus expressing either shCtrl,or shATF4. Top, Representative traces of mIPSCs recorded from shCtrl (black traces) or shATF4 (red traces) infected neurons alone (shCtrl, $n=49 ;$ shATF4, $n=29$ ) or in the presence of $20 \mu \mathrm{m}$ baclofen (GABA Ragonist; shCtrl, $n=16 ;$;hATF4, $n=15$ ), $10 \mu \mathrm{m} \mathrm{SCH50911} \mathrm{(GABA}{ }_{B}$ R antagonist; shCtrl, $n=36$; shATF4, $n=18$ ), or $100 \mu \mathrm{m}$ CGP55845 (GABA $\mathrm{B}_{\mathrm{B}}$ antagonist; shCtrl, $n=21$; shATF4, $n=17$ ). Bottom, Bar graphs represent the frequency (left) and the amplitude (right) of the mIPSCS. Data are mean \pm SEM. ${ }^{*} p<0.05 ;{ }^{* *} p<0.01$.

0.01), thus confirming that the membrane-bound $\mathrm{GABA}_{\mathrm{B}} \mathrm{Rs}$ of shATF4-infected hippocampal neurons are properly responding to stimulation. Interestingly, the application of $\mathrm{GABA}_{\mathrm{B}} \mathrm{R}$ antagonists CGP55845 and SCH50911 significantly elevated mIPSC frequency in shCtrl but not in shATF4 neurons (Fig. $5 B$; shCtrl $+\mathrm{SCH}=3.19 \pm 0.30 \mathrm{~Hz}, \operatorname{shCrl}+\mathrm{CGP}=3.67 \pm 0.46 \mathrm{~Hz}$, shATF4 + SCH $=3.38 \pm 0.44 \mathrm{~Hz}$, shATF4+CGP $=3.59 \pm 0.15$ $\mathrm{Hz}$; post hoc Bonferroni: shCtrl vs shCtrl $+\mathrm{SCH}, p<0.05$; shCtrl vs shCtrl+CGP, $p<0.05$; shATF4 vs shATF4 + SCH, shATF4 vs shATF4+CGP, $p>0.05$ ), which is consistent with the observa- tion that shATF4 reduces membrane-bound levels of $\mathrm{GABA}_{\mathrm{B}} \mathrm{Rs}$. As expected, none of the treatments significantly affected the amplitude of mIPSCs (Fig. 5B).

The effects of ATF4 on excitability and $G A B A_{B} R s$ appear to be mediated by changes in Cdc42 expression

We previously reported that ATF4's modulation of dendritic spine density and glutamatergic functionality is mediated, at least in part, by its capacity to regulate the stability and expression of the total and activated forms of the small Rho GTPase Cdc42 (Liu 


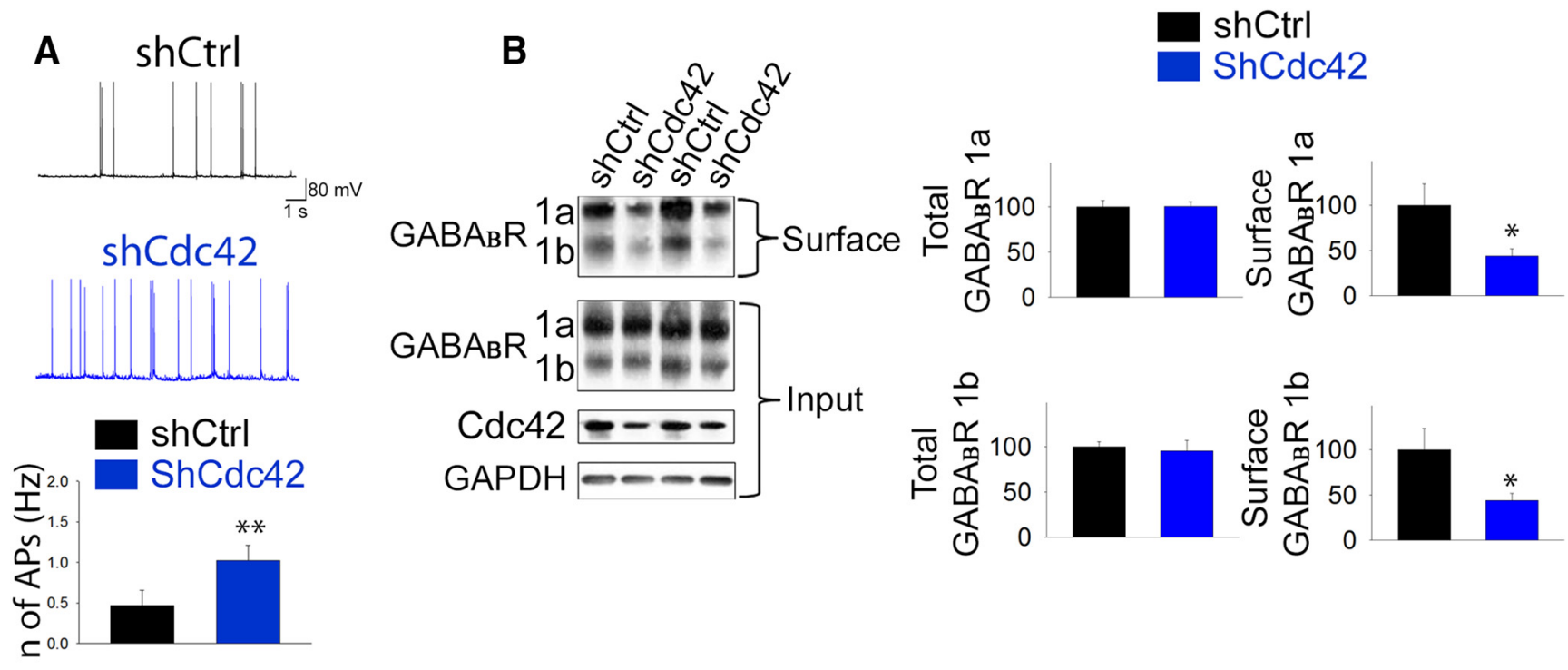

C
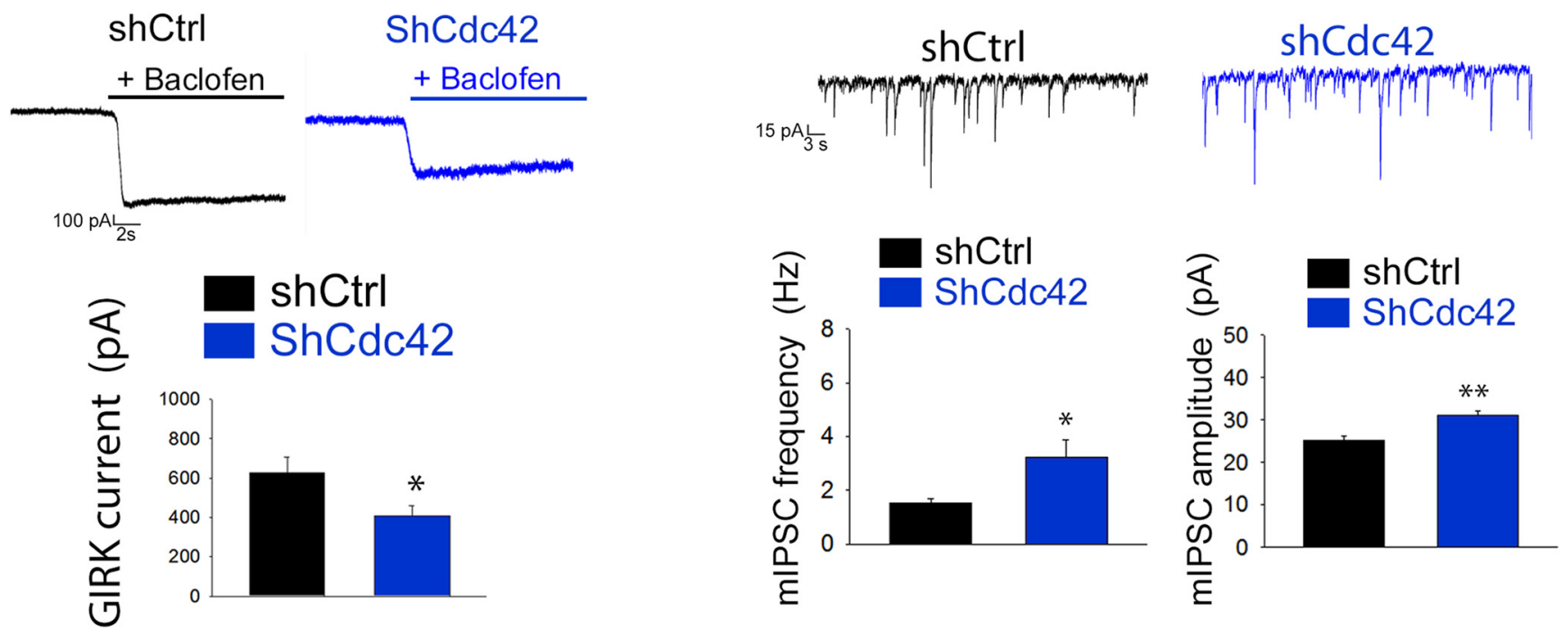

Figure 6. The effects of $A T F 4$ on excitability and $G_{A B A} B s$ are driven by changes in $(d c 42$ expression. $A$, $C d c 42$ downregulation increases intrinsic neuronal excitability. Top, Representative traces of $s A P$ s recorded from cultured hippocampal neurons infected at 7 DIV for 2 weeks with lentivirus expressing either shCtrl (black trace) or shCdc42 (blue trace). Bottom, Summary bar graphs represent the frequency of $s$ APs of neurons infected with shCtrl (black bars, $n=13$ ) or shCdc42 (blue bars, $n=13$ ) constructs. $B$, Cdc42 downregulation decreases membrane but not total GABA $A_{B} R$ levels. The 7 DIV cultured hippocampal neurons were infected with different lentiviral constructs (black represents shCtrl; blue represents shCdc42) for 2 weeks before undergoing extraction of total and membrane proteins. Left, Representative Western immunoblot. Right, Bar graphs represent densitometric analysis of immunoblots for total (left) or membrane (right) $\mathrm{GABA}_{\mathrm{B}} \mathrm{R} 1 \mathrm{a}$ and $1 \mathrm{~b}$ protein, normalized to GAPDH.C, Cdc42 downregulation decreases baclofen-elicited GIRK currents. Top, Representative traces of baclofen-elicited currents recorded from 7 DIV cultured hippocampal neurons infected for 2 weeks with lentivirus carrying either shCtrl (black) or shCdc42 (blue). Bottom, Bar graph represents the measurements of the currents (shCtrl, $n=22 ;$ shCdc42, $n=26)$. D, Cdc 42 downregulation increases mIPSCs. Top, Representative mIPSC traces recorded from 7 DIV hippocampal neurons infected for 2 weeks with lentivirus carrying either shCtrl (black) or shCdc42 (blue)

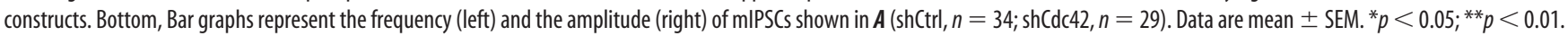

et al., 2014; Pasini et al., 2015). Of particular relevance here, Cdc42 has been shown to be involved in regulating receptor trafficking (Hussain et al., 2015). We therefore next tested the hypothesis that the effects of ATF4 downregulation on $G_{A B A} R$ trafficking and neuronal excitability could be mediated by loss of Cdc42. To achieve this, we used a previously characterized Cdc42 shRNA (Liu et al., 2014) to deplete Cdc42 in cultured hippocampal neurons and determined whether this phenocopies the effects of ATF4 knockdown. We first assessed whether specific Cdc42 downregulation affects neuronal excitability. As in the case of ATF4 knockdown, silencing Cdc42 protein produced a twofold increase of AP frequency (Fig. $6 \mathrm{~A}$; shCtrl $=0.43 \pm 0.13 \mathrm{~Hz}$,
shCdc42 $=1.08 \pm 0.15 \mathrm{~Hz} ; t$ test, $p<0.01)$. Next, we queried whether Cdc42 downregulation phenocopies the effect of ATF4 knockdown on $\mathrm{GABA}_{\mathrm{B}} \mathrm{R}$ trafficking and found that this was sufficient to significantly decrease the levels of membrane-exposed, but not total $\mathrm{GABA}_{\mathrm{B}}$ Rs (Fig. $6 \mathrm{~B}$; for $\mathrm{GABA}_{\mathrm{B}} \mathrm{R}$ 1a shCtrl $=100 \pm$ $23.3 \%$, shCdc42 $44.2 \pm 7.4 \%$; $t$ test, $p<0.05 ; \mathrm{GABA}_{\mathrm{B}} \mathrm{R} 1 \mathrm{~b}$ shCtrl $=100 \pm 20.3 \%, \operatorname{shCdc} 4238.7 \pm 4.7 \%$; $t$ test, $p<0.05$ ). In addition, we found that baclofen-induced GIRK currents were significantly decreased in shCdc42-infected neurons, compared with controls (Fig. $6 C$; shCtrl $=627.8 \pm 77.6 \mathrm{pA}$, shCdc42 $=$ $406.9 \pm 52.9 \mathrm{pA} ; t$ test, $p<0.05$ ). Finally, Cdc42 knockdown also increased the frequency mIPSCs (Fig. $6 D$; shCtrl $=1.55 \pm 0.16$ 
$\mathrm{Hz}, \operatorname{shCdc} 42=3.21 \pm 0.67 \mathrm{~Hz}$; $t$ test, $p<0.05)$ to a degree similar to that observed with ATF4 knockdown. However, with Cdc42 knockdown, there was also a small, but significant, increase in mIPSC amplitude (Fig. $6 D$; shCtrl $=25.22 \pm 1.26 \mathrm{pA}$, shCdc $42=$ $31 \pm 1.21 \mathrm{pA} ; t$ test, $p<0.01)$. Together, these findings support the idea that regulation of Cdc42 levels mediates the effects of ATF4 on neuronal $\mathrm{GABA}_{\mathrm{B}} \mathrm{R}$ trafficking and excitability.

\section{Discussion}

In the present study, we delineate a novel role for the transcription factor ATF4 in regulating $\mathrm{GABA}_{\mathrm{B}} \mathrm{R}$ trafficking and neuronal excitability. Our data show that chronic ATF4 downregulation in hippocampal neurons reduces membrane levels of $\mathrm{GABA}_{\mathrm{B}} \mathrm{Rs}$, diminishes their functionality, and consequently leads to a substantial increase of neuronal firing rate. In addition, we found that these effects are mediated by ATF4's transcriptional capability and reflect changes in expression of the small GTPase Cdc42. Studies on ATF4's role in the regulation of synaptic plasticity and memory have led to divergent views. ATF4 has been characterized to be either a negative or positive influence on plasticity. Such interpretations appear to be dependent on cellular context (Bartsch et al., 1995; Hu et al., 2015) or have been based on experimental manipulations that are not specific to ATF4, such as use of a dominant-negative construct (Chen et al., 2003) or regulation of eIF $2 \alpha$ phosphorylation (Costa-Mattioli et al., 2007). To more directly assess ATF4's function in unstressed brain, we have used the strategy of studying the effects of long-term ATF4 knockdown or deletion in hippocampal and cortical neurons both in vitro and in vivo. This has revealed required roles for ATF4 in maintaining mushroom spines and glutamatergic functionality as well as in long-term spatial memory and behavioral flexibility (Liu et al., 2014; Pasini et al., 2015). The present findings significantly extend the range of cognition-relevant neuronal properties that are dependent on the presence of ATF4.

In the present work, we found that ATF4 plays a novel role in regulating the proportion of $\mathrm{GABA}_{\mathrm{B}} \mathrm{Rs}$ that are exposed on the neuronal surface. Two subunit isoforms of $\mathrm{GABA}_{\mathrm{B}} 1$ receptors have been described, $G_{A B A} R$ la and $G_{A B A} R 1 b$, which differ by the presence of two sushi domains near the $\mathrm{N}$ terminus of $\mathrm{GABA}_{\mathrm{B}} \mathrm{R}$ 1a (Hawrot et al., 1998). Our findings indicate that ATF4 knockdown leads to comparable reductions of both $\mathrm{GABA}_{\mathrm{B}} \mathrm{R} 1 \mathrm{a}$ and $\mathrm{GABA}_{\mathrm{B}} \mathrm{R} 1 \mathrm{~b}$ on the cell surface. There is evidence that $\mathrm{GABA}_{\mathrm{B}} \mathrm{R}$ la subunits are mainly located presynaptically, whereas $\mathrm{GABA}_{\mathrm{B}} \mathrm{R} 1 \mathrm{~b}$ subunits are predominantly expressed postsynaptically (Vigot et al., 2006). Consistent with this localization and with the reductions of both subunit types on the cell surface, we observed both an increase in the frequency of mIPSCs (which is mainly a presynaptic measurement) and a decrease of GIRK currents (mainly postsynaptic in origin) after ATF4 knockdown. Presynaptic $\mathrm{GABA}_{\mathrm{B}} \mathrm{Rs}$ act as presynaptic brakes on release of neurotransmitters (Sakaba and Neher, 2003; Laviv et al., 2010) and $\mathrm{GABA}_{\mathrm{B}} \mathrm{R}$ modulation consequently affects the frequency, but not the amplitude, of mIPSCs (Ulrich and Huguenard, 1996; Kubota et al., 2003; Kirmse and Kirischuk, 2006). Our observation that ATF4 downregulation increases the frequency, but not amplitude, of mIPSCs is thus consistent with a decrease of presynaptic surface-exposed $\mathrm{GABA}_{\mathrm{B}}$ Rs. Further supporting this view, we found that application of the specific $G_{A B A} R$ antagonists CGP55845 and SCH50911 significantly elevated mIPSC frequency in shCtrl- but not in shATF4-treated neurons, indicating that presynaptic $\mathrm{GABA}_{\mathrm{B}} \mathrm{R}$ activity is compromised in the ATF4 knockdown neurons.
Presynaptic and postsynaptic $\mathrm{GABA}_{\mathrm{B}} \mathrm{R}$ function has been widely reported to be associated with GIRKs, which hyperpolarize neurons in response to $\mathrm{GABA}_{\mathrm{B}} \mathrm{R}$ activation (Ladera et al., 2008). We therefore measured $G_{A B A} R$-induced $\mathrm{K}^{+}$currents as a readout of $\mathrm{GABA}_{\mathrm{B}} \mathrm{R}$ activity and found a $40 \%$ reduction of GIRK current in ATF4 downregulated neurons. These observations are consistent with a decline in trafficking of postsynaptic $\mathrm{GABA}_{\mathrm{B}}$ Rs. Thus, our findings suggest effects of ATF4 on both presynaptic and postsynaptic $\mathrm{GABA}_{\mathrm{B}} \mathrm{Rs}$. Additional studies will be needed to further characterize these effects and to define their individual influences on synaptic transmission.

In our study, we observed that the total and surface levels of GIRK proteins were unaltered by ATF4 downregulation; this finding suggests the idea that $\mathrm{GABA}_{\mathrm{B}}$ Rs and GIRK can be independently trafficked to the cell surface. In addition, our finding that ATF4 downregulation reduces GABABR functionality without affecting $G_{A B A_{B}} R 2$ levels is in line with the evidence that the 2 subunits $\left(G_{A B A} R 1\right.$ and 2$)$ need to heterodimerize to produce a functionally active $\mathrm{GABA}_{\mathrm{B}} \mathrm{R}$ (Jones et al., 1998).

A major issue addressed in our study is the mechanism by which ATF4 regulates the surface expression of $\mathrm{GABA}_{\mathrm{B}} \mathrm{Rs}$. As a leucine zipper protein, ATF4 has the capacity to undergo direct protein-protein interactions, among which is binding to $\mathrm{GABA}_{\mathrm{B}}$ Rs. However, this interaction did not appear to be relevant to the observed regulation of $\mathrm{GABA}_{\mathrm{B}} \mathrm{R}$ membrane trafficking because the deficits in this parameter were not rescued by a mutant ATF4 lacking DNA binding capacity but possessing an intact leucine zipper. These observations rather support a transcriptional role for ATF4 in regulating $\mathrm{GABA}_{\mathrm{B}} \mathrm{R}$ surface exposure. A prior study reported that ATF4 overexpression elevated expression of a $\mathrm{GABA}_{\mathrm{B}} \mathrm{R}$ 1a promoter-reporter construct and decreased expression of a $\mathrm{GABA}_{\mathrm{B}} \mathrm{R} 1 \mathrm{~b}$ promoter-reporter construct (Steiger et al., 2004). However, we noted no changes either in $\mathrm{GABA}_{\mathrm{B}} \mathrm{R}$ 1a or $\mathrm{GABA}_{\mathrm{B}} \mathrm{R} 1 \mathrm{~b}$ mRNA or total protein after ATF4 knockdown. Moreover, ATF4 overexpression also failed to affect surface or total $G_{A B A} R$ la or $G_{B B A} R$ lb levels in our experiments. Our findings instead indicate that the role of ATF4 in controlling $\mathrm{GABA}_{\mathrm{B}} \mathrm{R}$ trafficking stems from its transcriptiondependent capacity to regulate Cdc42 expression. In support of this idea, Cdc42 knockdown fully phenocopied the effects of ATF4 knockdown on surface expression of $\mathrm{GABA}_{\mathrm{B}}$ Rs. Although the ATF4/Cdc42 pathway appears to be a key player in $G_{A B A} R$ trafficking, this does not seem to be a universal mechanism for regulating receptor surface expression in neurons. Thus, ATF4 knockdown did not affect total or membrane expression of $\mathrm{GABA}_{\mathrm{B}} \mathrm{R} 2$, $\mathrm{GABA}_{\mathrm{A}} \beta 2$ and $\gamma 2$ subunits, or $\mathrm{K}_{\mathrm{v}} 1.1, \mathrm{~K}_{\mathrm{v}} 2.1, \mathrm{~K}_{\mathrm{v}} 4.2$, and $\mathrm{Ca}_{\mathrm{v}} 2.1$ channels. It remains to be seen whether the ATF4/Cdc42 pathway affects trafficking of other neurotransmitter receptors.

Cdc42-dependent signaling has been implicated in trafficking of GluA1 AMPA receptors (Hussain et al., 2015). One way in which the effect of Cdc42 knockdown differed from ATF4 knockdown was that the former, but not the latter, caused a small, but significant increase in the amplitude of mIPSCs. One possible explanation for this discrepancy may be the different magnitude of Cdc42 protein silencing exerted by the two shRNA constructs. Whereas shATF 4 caused an $\sim 40 \%-50 \%$ reduction of Cdc 42 protein, shCdc42 depleted $70 \%-80 \%$ of total Cdc42 protein. It may be that the greater loss of $\mathrm{Cdc} 42$ with shCdc42 results in postsynaptic modifications that affect GABA sensitivity.

Our findings establish roles for transcriptionally active ATF4 and for $\mathrm{Cdc} 42$ in regulation of $\mathrm{GABA}_{\mathrm{B}} \mathrm{R}$ trafficking. Our prior work has shown that ATF4 influences Cdc42 levels by promoting its stability and that this in turn reflects the Cdc42-stabilizing 


\section{Control}

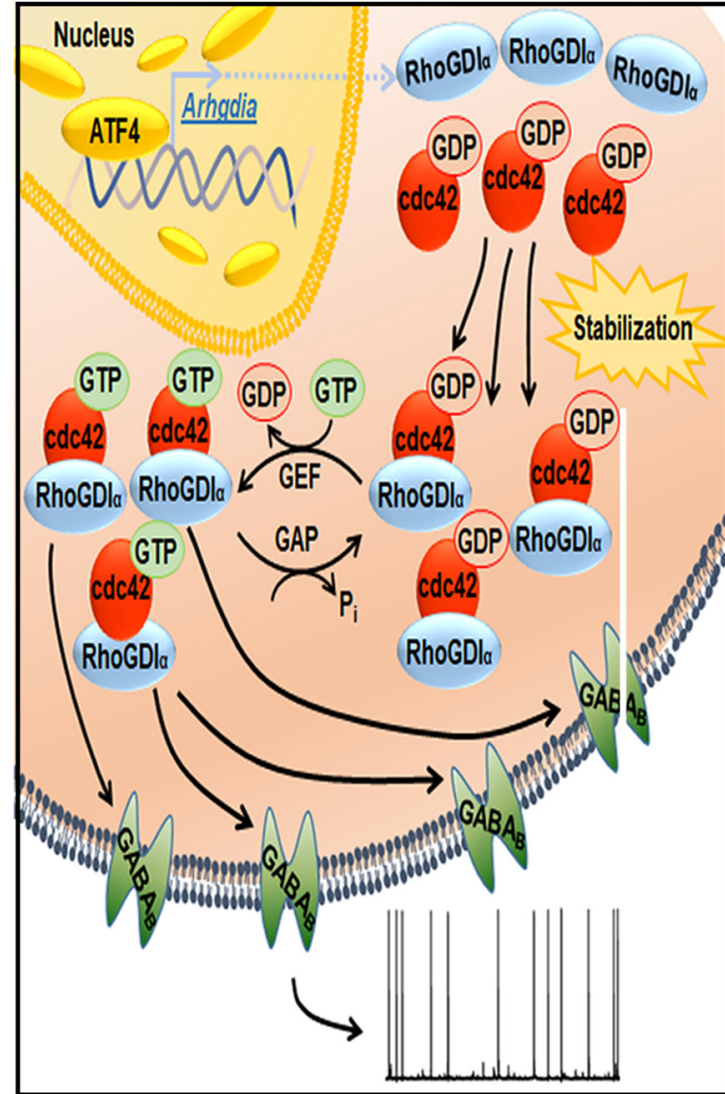

\section{Chronic ATF4 down-regulation}

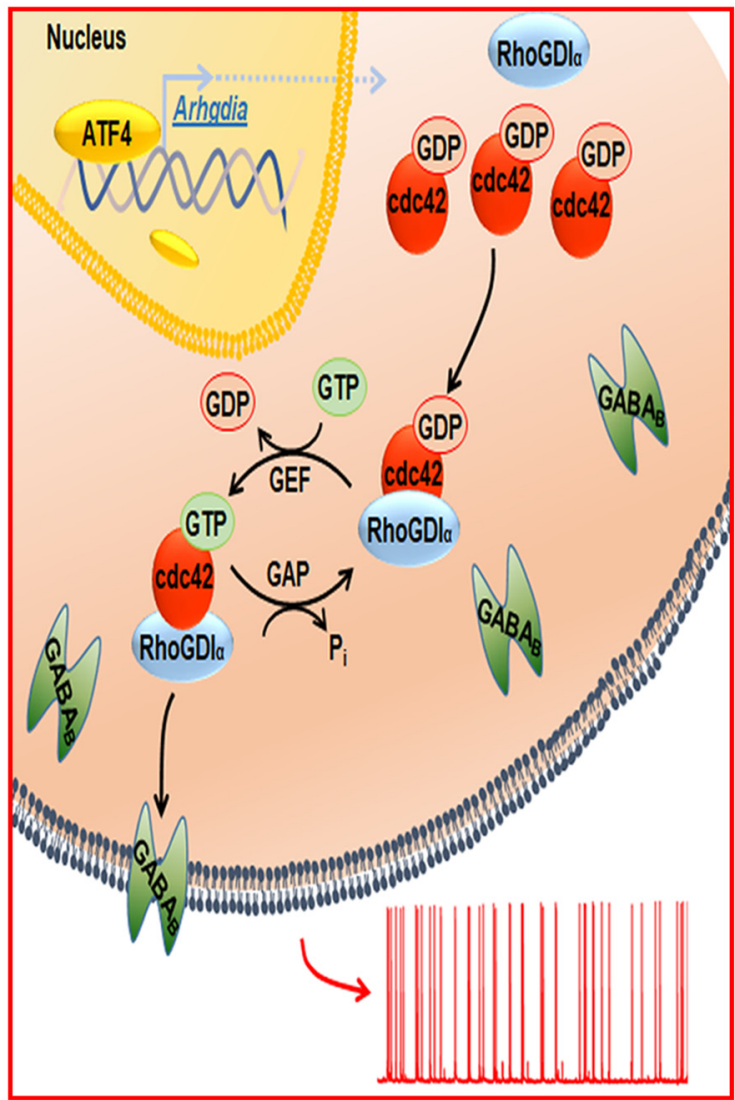

Figure 7. Proposed mechanism by which ATF4 regulates neuronal excitability. Left, Control condition where basal levels of ATF4 protein ensure the appropriate amount of RhoGDI $\alpha$ expression to bind and stabilize cytoplasmic Rho GTPase family members, including $\mathrm{Cd}\left(42\right.$. Appropriate levels of $\mathrm{Cd}\left(42\right.$ result in basal levels of membrane-bound GABA $\mathrm{B}_{\mathrm{B}}$ that contribute to control the pace of neuronal firing. Right, Condition of chronic ATF4 downregulation, the consequent decrease of RhoGDl $\alpha$ levels, and augmented Cdc42 turnover. This in turn negatively affects the amount of membrane-bound $\mathrm{GABA}_{B} \mathrm{Rs}$, altering neuronal intrinsic excitability properties, which results in increased sAP frequency.

activity of RhoGDI $\alpha$, a direct transcriptional target of ATF4 (Pasini et al., 2016). Figure 7 shows a proposed mechanistic pathway by which ATF4 regulates $\mathrm{GABA}_{\mathrm{B}} \mathrm{R}$ trafficking and neuronal excitability via Cdc 42 and RhoGDI $\alpha$. An important feature of this mechanism is that it appears to occur over a prolonged time course. Cdc42 is a relatively stable protein, and knocking down ATF4 in neurons reduces Cdc42's apparent half-life from 31.5 to $18.5 \mathrm{~h}$ (Liu et al., 2014). This suggests that sustained changes in ATF4 protein levels/activity over many hours may be required to materially affect Cdc42 expression and thereby to affect synaptic activity. ATF4 itself is a rapidly turning-over protein, and its expression is regulated both by translational and transcriptional mechanisms. Thus, ATF4 may serve as a "sentinel" protein whose ambient expression levels in neurons influence $\mathrm{GABA}_{\mathrm{B}} \mathrm{R}$ trafficking as well as other elements of neuronal plasticity.

\section{References}

Ameri K, Harris AL (2008) Activating transcription factor 4. Int J Biochem Cell Biol 40:14-21. CrossRef Medline

Bartsch D, Ghirardi M, Skehel PA, Karl KA, Herder SP, Chen M, Bailey CH, Kandel ER (1995) Aplysia CREB2 represses long-term facilitation: relief of repression converts transient facilitation into long-term functional and structural change. Cell 83:979-992. CrossRef Medline

Bean BP (2007) The action potential in mammalian central neurons. Nat Rev Neurosci 8:451-465. CrossRef Medline
Beck H, Yaari Y (2008) Plasticity of intrinsic neuronal properties in CNS disorders. Nat Rev Neurosci 9:357-369. CrossRef Medline

Chen A, Muzzio IA, Malleret G, Bartsch D, Verbitsky M, Pavlidis P, Yonan AL, Vronskaya S, Grody MB, Cepeda I, Gilliam TC, Kandel ER (2003) Inducible enhancement of memory storage and synaptic plasticity in transgenic mice expressing an inhibitor of ATF4 (CREB-2) and C/EBP proteins. Neuron 39:655-669. CrossRef Medline

Chen X, Yuan LL, Zhao C, Birnbaum SG, Frick A, Jung WE, Schwarz TL, Sweatt JD, Johnston D (2006) Deletion of Kv4.2 gene eliminates dendritic A-type $\mathrm{K}^{+}$current and enhances induction of long-term potentiation in hippocampal CA1 pyramidal neurons. J Neurosci 26:1214312151. CrossRef Medline

Costa-Mattioli M, Gobert D, Stern E, Gamache K, Colina R, Cuello C, Sossin W, Kaufman R, Pelletier J, Rosenblum K, Krnjević K, Lacaille JC, Nader K, Sonenberg N (2007) eIF2alpha phosphorylation bidirectionally regulates the switch from short- to long-term synaptic plasticity and memory. Cell 129:195-206. CrossRef Medline

Deroanne CF, Hamelryckx D, Ho TT, Lambert CA, Catroux P, Lapiére CM, Nusgens BV (2005) Cdc42 downregulates MMP-1 expression by inhibiting the ERK1/2 pathway. J Cell Sci. 118(Pt 6):1173-1183. CrossRef Medline

Gassmann M, Bettler B (2012) Regulation of neuronal GABA(B) receptor functions by subunit composition. Nat Rev Neurosci 13:380-394. CrossRef Medline

Hawrot E, Xiao Y, Shi QL, Norman D, Kirkitadze M, Barlow PN (1998) Demonstration of a tandem pair of complement protein modules in GABA(B) receptor 1a. FEBS Lett 432:103-108. CrossRef Medline 
Hsiao CF, Kaur G, Vong A, Bawa H, Chandler SH (2009) Participation of Kv1 channels in control of membrane excitability and burst generation in mesencephalic V neurons. J Neurophysiol 101:1407-1418. CrossRef Medline

Hu JY, Levine A, Sung YJ, Schacher S (2015) cJun and CREB2 in the postsynaptic neuron contribute to persistent long-term facilitation at a behaviorally relevant synapse. J Neurosci 35:386-395. CrossRef Medline

Hussain NK, Thomas GM, Luo J, Huganir RL (2015) Regulation of AMPA receptor subunit GluA1 surface expression by PAK3 phosphorylation. Proc Natl Acad Sci U S A 112:E5883-E5890. CrossRef Medline

Jones KA, Borowsky B, Tamm JA, Craig DA, Durkin MM, Dai M, Yao WJ, Johnson M, Gunwaldsen C, Huang LY, Tang C, Shen Q, Salon JA, Morse K, Laz T, Smith KE, Nagarathnam D, Noble SA, Branchek TA, Gerald C (1998) GABA(B) receptors function as a heteromeric assembly of the subunits GABA(B)R1 and GABA(B)R2. Nature 396:674-679. CrossRef Medline

Kim IH, Wang H, Soderling SH, Yasuda R (2014) Loss of Cdc42 leads to defects in synaptic plasticity and remote memory recall. Elife 3.

Kirmse K, Kirischuk S (2006) Ambient GABA constrains the strength of GABAergic synapses at Cajal-Retzius cells in the developing visual cortex. J Neurosci 26:4216-4227. CrossRef Medline

Kubota H, Katsurabayashi S, Moorhouse AJ, Murakami N, Koga H, Akaike N (2003) GABAB receptor transduction mechanisms, and cross talk between protein kinases A and $\mathrm{C}$, in GABAergic terminals synapsing onto neurons of the rat nucleus basalis of Meynert. J Physiol 551:263-276. CrossRef Medline

Ladera C, del Carmen Godino M, Jose Cabanero M, Torres M, Watanabe M, Lujan R, Sánchez-Prieto J (2008) Pre-synaptic GABA receptors inhibit glutamate release through GIRK channels in rat cerebral cortex. J Neurochem 107:1506-1517. CrossRef Medline

Laviv T, Riven I, Dolev I, Vertkin I, Balana B, Slesinger PA, Slutsky I (2010) Basal GABA regulates $\mathrm{GABA}(\mathrm{B}) \mathrm{R}$ conformation and release probability at single hippocampal synapses. Neuron 67:253-267. CrossRef Medline

Leung LS, Peloquin P (2006) GABA(B) receptors inhibit backpropagating dendritic spikes in hippocampal CA1 pyramidal cells in vivo. Hippocampus 16:388-407. CrossRef Medline

Liu J, Pasini S, Shelanski ML, Greene LA (2014) Activating transcription factor 4 (ATF4) modulates post-synaptic development and dendritic spine morphology. Front Cell Neurosci 8:177. CrossRef Medline

Nehring RB, Horikawa HP, El Far O, Kneussel M, Brandstätter JH, Stamm S, Wischmeyer E, Betz H, Karschin A (2000) The metabotropic GABAB receptor directly interacts with the activating transcription factor 4. J Biol Chem 275:35185-35191. CrossRef Medline

Pasini S, Corona C, Liu J, Greene LA, Shelanski ML (2015) Specific downregulation of hippocampal ATF4 reveals a necessary role in synaptic plasticity and memory. Cell Rep 11:183-191. CrossRef Medline

Pasini S, Liu J, Corona C, Peze-Heidsieck E, Shelanski M, Greene LA (2016)
Activating transcription factor 4 (ATF4) modulates $\rho$ GTPase levels and function via regulation of RhoGDIalpha. Sci Rep 6:36952. CrossRef Medline

Ritter B, Zschüntsch J, Kvachnina E, Zhang W, Ponimaskin EG (2004) The $\mathrm{GABA}(\mathrm{B})$ receptor subunits $\mathrm{R} 1$ and $\mathrm{R} 2$ interact differentially with the activation transcription factor ATF4 in mouse brain during the postnatal development. Brain Res Dev Brain Res 149:73-77. CrossRef Medline

Rossignol E, Kruglikov I, van den Maagdenberg AM, Rudy B, Fishell G (2013) CaV 2.1 ablation in cortical interneurons selectively impairs fastspiking basket cells and causes generalized seizures. Ann Neurol 74:209222. CrossRef Medline

Sakaba T, Neher E (2003) Direct modulation of synaptic vesicle priming by GABA(B) receptor activation at a glutamatergic synapse. Nature 424:775778. CrossRef Medline

Speca DJ, Ogata G, Mandikian D, Bishop HI, Wiler SW, Eum K, Wenzel HJ, Doisy ET, Matt L, Campi KL, Golub MS, Nerbonne JM, Hell JW, Trainor BC, Sack JT, Schwartzkroin PA, Trimmer JS (2014) Deletion of the Kv2.1 delayed rectifier potassium channel leads to neuronal and behavioral hyperexcitability. Genes Brain Behav 13:394-408. CrossRef Medline

Steiger JL, Bandyopadhyay S, Farb DH, Russek SJ (2004) cAMP response element-binding protein, activating transcription factor-4, and upstream stimulatory factor differentially control hippocampal GABABR1a and GABABR1b subunit gene expression through alternative promoters. J Neurosci 24:6115-6126. CrossRef Medline

Ulrich D, Huguenard JR (1996) Gamma-aminobutyric acid type B receptor-dependent burst-firing in thalamic neurons: a dynamic clamp study. Proc Natl Acad Sci U S A 93:13245-13249. CrossRef Medline

Vernon E, Meyer G, Pickard L, Dev K, Molnar E, Collingridge GL, Henley JM (2001) GABA(B) receptors couple directly to the transcription factor ATF4. Mol Cell Neurosci 17:637-645. CrossRef Medline

Vigot R, Barbieri S, Bräuner-Osborne H, Turecek R, Shigemoto R, Zhang YP, Luján R, Jacobson LH, Biermann B, Fritschy JM, Vacher CM, Müller M, Sansig G, Guetg N, Cryan JF, Kaupmann K, Gassmann M, Oertner TG, Bettler B (2006) Differential compartmentalization and distinct functions of GABAB receptor variants. Neuron 50:589-601. CrossRef Medline

White JH, McIllhinney RA, Wise A, Ciruela F, Chan WY, Emson PC, Billinton A, Marshall FH (2000) The GABAB receptor interacts directly with the related transcription factors CREB2 and ATFx. Proc Natl Acad Sci U S A 97:13967-13972. CrossRef Medline

Zapata J, Moretto E, Hannan S, Murru L, Longatti A, Mazza D, Benedetti L, Fossati M, Heise C, Ponzoni L, Valnegri P, Braida D, Sala M, Francolini M, Hildebrand J, Kalscheuer V, Fanelli F, Sala C, Bettler B, Bassani S, et al. (2017) Epilepsy and intellectual disability linked protein Shrm4 interaction with GABABRs shapes inhibitory neurotransmission. Nat Commun 8:14536. CrossRef Medline 